\title{
Risk assessment and analysis of harmful residues in edible agricultural products in China-take Anhui Province as an example
}

\author{
Wei $X u^{1,2}$ (D) Tao Sun ${ }^{1}$ \\ Received: 15 March 2021 / Accepted: 4 August 2021 / Published online: 16 August 2021 \\ (C) The Author(s), under exclusive licence to Springer-Verlag GmbH Germany, part of Springer Nature 2021
}

\begin{abstract}
The reforming and opening-up and the development of agricultural science and technology have brought about the rapid growth of China's food quantity and solved the problem that $20 \%$ of the world's population has enough to eat. At the same time, it also brings the problem of harmful residues in food. On the one hand, the Chinese government guides farmers to rationally use chemical fertilizers, pesticides, and veterinary drugs. On the other hand, in urban and rural school canteens and farmers' markets in third-tier cities, the implementation of pesticide residue detection system. Through the investigation of 24 kinds of edible agricultural products which are easy to produce harmful residues, and using a variety of statistical methods, the results showed that at present, the residues of harmful substances in edible agricultural products consumed by urban residents and school canteens in urban and rural areas have been well controlled, and the compliance rate is about $80 \%$. The residues of harmful substances in edible agricultural products consumed by rural residents obviously exceed the standard. Taking rice production as an example, although farmers can reduce the risk of excessive pesticide residues in rice through rational application of pesticides, they are more worried about less application of pesticides and bear the risk of reducing rice production. Most farmers still choose to take the risk of excessive pesticide residues.
\end{abstract}

Keywords Edible agricultural products $\cdot$ Residue of harmful substances $\cdot$ Rapid detection $\cdot$ Production function $\cdot$ Comprehensive evaluation

\section{Introduction}

Edible agricultural products refer to primary food from agriculture, forestry, animal husbandry, sideline and fishery industries and food only after superficial processing, also known as raw food, including grain, vegetables, livestock and poultry meat, eggs, soy products, and fruits. Before the 1970s, due to the backward agricultural production, China's basic living materials had been in a state of insufficient supply, and it

Responsible Editor: Philippe Garrigues

Wei Xu

xuweiacca@sina.com

Tao Sun

nuaasuntao@protonmail.com

1 School of Economics and Management, Nanjing University of Aeronautics \& Astronautics, Nanjing 210016, China

2 School of Accounting, Nanjing Audit University, Nanjing 211815, China had always been the focus of the Chinese government's work to let the people have enough to eat. China's economic reforming and opening-up has promoted the development of agricultural science and technology and accelerated the process of agricultural mechanization. In 1979, the land contract responsibility system was fully implemented in rural areas, which released a large number of surplus labor force in rural areas and activated the rural economy. With the rapid development of the production level of edible agricultural products, grain and various agricultural related materials have gradually enriched, and the supply bills of various materials have been cancelled successively in the 1990s. China's population accounts for $20 \%$ of the world's total, and its cultivated land is less than $7 \%$ of the world's total. Food self-sufficiency has always been a major strategic issue related to social stability. "Who will feed China" has once become the focus of global public opinion. From 2004 to 2015, China's grain production increased from $4.31 \times 10^{8} t$ to $6.21 \times 10^{8} t$, achieving a "twelve consecutive increase" in grain production, laying a solid material foundation for the healthy development of China's economy in the new era (Sun and Wang 2018). The national 
"Thirteenth Five-Year Plan" proposes a "strategy to ensure basic self-sufficiency of grains and absolute safety of rations", which clearly states the importance of ensuring safe food production (Yang et al. 2019). However, the development of science and technology not only brings benefits to people, but also brings many negative effects, such as the application of chemical fertilizers and pesticides, which greatly improves the output of agricultural products, but excessive application will form harmful residues in food. In 2015, China's total use of chemical fertilizers and pesticides exceeded 60 million tons and 1.8 million tons, accounting for $7 \%$ of the world's arable land. However, China invested more than $33 \%$ of the world's total amount of chemical fertilizers and pesticides, which is three times of the world average level and two times of the developed countries in Europe and America (Zhang et al. 2019). Shijiazhuang Sanlu Group, which was exposed in September 2008, used toxic melamine to increase the detection value of protein in milk powder. Since then, it has revealed the inside story of someone using high technology to carry out food counterfeiting, for example, feed "vegetarian meat essence" and growth-stimulating hormone to breeding animals. In order to prevent the death of fish in the process of transportation, operators add copper sulfate in the water of fish culture. On June 11, 2020, CCTV2 "Economic Information Broadcast" column reported that the criminal gang used industrial dilute sulfuric acid and homemade acid preservative to soak fruit "rambutan" to prolong the preservation time, and was arrested by Hangzhou police. Food safety has been concerned by the general public. In February 2009, China promulgated the first "Food Safety Law of the People's Republic of China". Then, more than 12600 national and industrial standards for agriculture have been formulated, of which more than $52 \%$ are national standards, and more than $85 \%$ are pesticide and veterinary drug residue limit standards. The maximum residue limits of pesticides in food (GB2763-2014) specifies the maximum dosage and residue of 387 pesticides. Under the severe crackdown of the government, there are far fewer cases of drug abuse directly in food, but the problem food is still being detected. Food safety problems are mainly caused by excessive levels of chemical fertilizers, pesticides and veterinary drug residues in agricultural products, and there is no effective control method. For example, in June 2016, Jinan City of Shandong Province announced a batch of unqualified agricultural products: Malachite green (including recessive malachite green) was not qualified in one batch of Acanthopanax japonicus in Huaiyin District. Furazolidone metabolite (AOZ) was detected in a batch of pork tenderloin from Runhui supermarket in Tianqiao District. Salbutamol clenbuterol was detected in a batch of raw pork from Shandong Jinze technical school in Licheng District, and one batch of Zucchini in Gaoer central kindergarten, Zhonggong Town, Licheng District, was found to have pesticide residues exceeding the standard. On June 9, 2020,
Dongguan City, Guangdong Province, sampled 8 vegetables from the canteen of a children's products Co., Ltd. with 2000 people (known as food safety level I) in Yinhe Industrial Zone, Qingxi Town. The results showed that the pesticide residues of red pepper, green pepper and celery were unqualified. On April 18, 2015, cctv13 reported that the research group of School of Public Health of Shanghai Fudan University has been monitoring the urine of more than 1000 school children aged 8 to 11 in Shanghai, Jiangsu and Zhejiang for more than 1 year. One antibiotic was detected in $58 \%$, more than two antibiotics were detected in $1 / 4$, and six antibiotics were detected in some samples. These include tylosin, chlortetracycline and enrofloxacin for livestock and poultry. It has become an objective fact that the residues of harmful substances in many edible agricultural products in China seriously exceed the standard.

In Europe and the USA and other developed countries, planting and breeding are generally operated by a small number of large farms or farms. The government mainly supervises and restricts the use of pesticides and veterinary drugs in the production process of farms and farms through professional associations. In particular, the food safety standards of European and American countries are relatively high, and the food violations detected will be severely cracked down (Bernd 2015). Many countries in the European Union carry out routine detection of pesticide residues in the market food. Most of the results show that $80 \%$ of the food has not been detected pesticide residues, $15-18 \%$ of the food can be detected pesticide residues less than the maximum limit, and only less than $3 \%$ (usually less than 1\%) of the food pesticide residues exceed the maximum limit. As China's agriculture and aquaculture are mainly run by scattered farmers independently, it is difficult for the government to directly supervise the production process (Schreinemachers and Tipraqsa 2012). The land contract responsibility system has lost its superiority, and now it has become an obstacle to the further development of agriculture. To solve the problem of pesticide residues, the Chinese government controls the production and marketing of edible agricultural products: (1) The Ministry of Agriculture has formulated a series of policies to control illegal operation of chemical fertilizers, pesticides and veterinary drugs, such as pesticide and veterinary drug franchise license system. Standards for rational and precise use of chemical fertilizers and pesticides have also been formulated. (2) Around 2008, Tianjin, Beijing and other first-tier cities began to carry out random inspection of edible agricultural products in major agricultural markets, and indirectly supervise the quality of edible agricultural products through sales channels. However, this kind of food has a large market supply, a wide range of varieties, and many market operators. In fact, retailers are not very clear about whether the harmful substances in the daily wholesale food exceed the standard. Moreover, it is extremely difficult to accurately analyze the organic compounds. 
Although the vast majority of harmful residues can be detected, the conventional detection of many residues requires expensive, large and cumbersome equipment, which requires skilled professional and technical personnel to operate. It can only be carried out in the laboratory, and it takes almost half a day for a sample to be accurately analyzed in the laboratory. So, at that time, only a few hundred cases were sampled every year in general cities, which was basically symbolic testing. In recent years, scientific and technological workers all over the world have explored some new rapid detection methods with strong specificity, high sensitivity, convenience, safety and low cost, such as enzyme inhibition method, immunoassay, biosensor and other rapid detection technologies for pesticide and veterinary drug residues, and the amount of samples extracted has greatly increased. At present, the "Smart Agricultural Trade Data Center" has been set up in the regular farmers' markets in China's third-tier cities and above, which can receive reports from consumers every day or randomly select some food stalls for rapid screening. After the rapid detection method, the negative samples can pass directly, and the names of qualified stalls and food can be published through video. The samples that are positive by the rapid detection method are generally tested again. For the food that is unqualified after three times of testing, the operator is required to explain the source and destroy it or dispose it innocuously under the supervision of the testing personnel. If the unqualified food is found, the operator may apply to send it to a professional laboratory for re-inspection. If the re-inspection is still unqualified, the re-inspection fee shall be borne by the applicant. In addition, the drug and food regulatory departments at all levels shall carry out sampling inspection and supervision on the food in the canteens of various schools and hospitals within their jurisdiction.

\section{Research background}

\section{Brief description of relevant research literature}

At present, the research on the residues of harmful substances in edible agricultural products mainly includes three aspects: (1) The harm of excessive application of chemical fertilizer. Nitrite and cadmium in fertilizer are the main culprits of cancer (Velthof et al. 2009). The composition of chemical fertilizer is monotonous. Even compound chemical fertilizer can only provide some kinds of main nutrients, but cannot provide all kinds of nutrients needed for crop growth. Long-term application of chemical fertilizer results in the lack of organic matter and trace elements in the soil, which affects the normal growth and development of plants (Sun 2010). Yan M. (2014) conducted an experiment on the effect of combined application of organic fertilizer and chemical fertilizer on rice, and concluded that the combined application of organic fertilizer and chemical fertilizer was not only conducive to soil fertility, but also improved the quality of rice, and the greater the proportion of organic fertilizer, the better the effect. Li Z. (20092012) conducted experiments on winter wheat and summer maize at the same time, using chemical fertilizer and organic fertilizer according to different proportions, the results showed that the yield of organic fertilizer combined with chemical fertilizer was better than that of chemical fertilizer alone, and the yield of winter wheat with $25 \%$ organic fertilizer was the highest, and that of summer maize with $50 \%$ organic fertilizer was the highest. (2) The problem of excessive application of pesticides. For example, Schreinemachers and Tipraqsa (2012), according to the data of pesticide application in various countries from 1990 to 2009 collected by the Food and Agriculture Organization of the United Nations (FAO), considered that the growth of pesticide application intensity was negatively correlated with the level of national economic development, the growth of pesticide application intensity in developed countries was slow, and the application intensity in some developed countries had begun to decline. Jacquet et al. (2011) studied the relevant policies of government intervention on farmers' pesticide application behavior, established a model to study the potential of pesticide reduction in France, and proposed that under the premise of ensuring that farmers' income is not affected, training and education can reduce the pesticide application by $10 \%$, especially combined with long-term scientific and technological progress, the pesticide application in France may be reduced by $30 \%$. Huang and Chen (2008) discussed the impact of farmers' technical information and preferences on pesticide application intensity. Wang and Gu (2013) conducted a survey on some vegetable farmers in Jiangsu Province. They believed that the benefits of pesticides from reducing the yield of vegetables were greater than the cost of pesticides. They also proposed that if the residues of pesticides in vegetables would reduce the price of vegetables, farmers might reduce the amount of pesticides. Tang et al. (2012) sprayed chlorothalonil and chlorpyrifos on cucumber in open air and greenhouse according to the recommended standard of the manual. The results showed that (a) pesticide residues were leaf $>$ fruit $>$ stem $>$ root. (b) After 14 days, chlorothalonil and chlorpyrifos residues were $7.86 \mathrm{mg} / \mathrm{kg}$ and $1.01 \mathrm{mg} / \mathrm{kg}$ respectively, far exceeding the national standard of $5 \mathrm{mg} / \mathrm{kg}$ and 0.1 $\mathrm{mg} / \mathrm{kg}$; after 7 days in the open air, chlorothalonil and chlorpyrifos residues were $4.46 \mathrm{mg} / \mathrm{kg}$ and $0.22 \mathrm{mg} / \mathrm{kg}$ respectively, which were lower than the national standard. Zhang et al. (2011) conducted experiments on rice using a variety of pesticides. The results showed that (a) $80 \%$ of pesticide residues were concentrated in rice husk and rice straw. (b) The pesticide residues in rice were much lower when applied before heading than after heading. Fu (2014) concluded that the degradation rate of chlorothalonil in cucumber and tomato in spring was faster than that in autumn, mainly because the 
temperature in spring was gradually warmer and that in autumn was gradually cooler. Some scholars discussed the degradation law of pesticides in agricultural products, and found that the residue rate $c$ of most pesticides in agricultural products and days after application $t$ were in accordance with the negative exponential regression equation $C=C_{0} e^{-k t} t$. For example, Feng et al. (2007) conducted a dynamic test of pesticide degradation on open-field cucumbers, using 4 insecticides chlorpyrifos, fenpropathrin, cypermethrin, and amacloprid and 3 fungicides chlorothalonil, thiophanate methyl, and copper oxychloride; as a result, the residue of each drug basically conforms to the negative exponential equation. For example, the residual rate equation of chlorpyrifos is $C=$ $1.5313 e^{-0.7665 t}$. Li et al. (2012) tested the dynamic changes of the residual rate of buprofezin in rice, simulated 5 models, and obtained the Rayleigh dynamic model with the highest accuracy $C=0.47662 t^{-0.21215 t} e^{-0.01542 t^{2}}$ (3) The residue of harmful substances in animal derived food. Cheng et al. (2017) discussed the issue of formaldehyde residues in aquatic products. He et al. (2013) discussed measures to ensure the safety of food of animal origin. However, no one has been involved in the assessment of the severity of harmful residues in edible agricultural products in China.

\section{Agricultural production environment in Anhui Province}

Anhui is located in Eastern China and is a typical inland province, straddling the Yangtze River and the middle and lower reaches of the Huai River. It connects with Jiangsu and Zhejiang in the east, Hubei and Henan in the west, Jiangxi in the south and Shandong in the north. The province has jurisdiction over 17 cities, including 104 districts (counties). The province can be roughly divided into five natural regions: Huaibei Plain, Jianghuai Hill, Dabie Mountain Area in West Anhui, Riverside Plain and Southern Anhui Mountain area. Plains, hills, and mountains each account for about one-third. Rich in agricultural resources and a large proportion of agricultural products, it is a typical agricultural province. According to the Provincial Statistics Bureau, the province has a land area of $139,600 \mathrm{~km}^{2}$, including 88 million mu of arable land, 56 million mu of woodland, and 8.7 million mu of water surface for breeding. The province's permanent population is about 61 million, of which the rural population is about 53 million. The agricultural climatic conditions are suitable, the annual average temperature is $14-17^{\circ}$, and the annual rainfall is $700-1700 \mathrm{~mm}$. There are abundant agricultural species resources, including 3200 species of wild plants and more than 500 species of wild animals. Anhui is a major grainproducing province in the country. The annual crop planting area exceeds 130 million mu, of which the area of grain crops accounts for more than $75 \%$, and the total output is 35 million tons. The area ranks fourth in the country and the total output ranks $6-8$ in the country. The main grain crops are wheat, rice, corn, soybeans, potatoes and other dry grain crops. Among them, the annual sown area of wheat is 36.5 million mu, with a total output of 14 million tons; the area of rice is 34.5 million mu with a total output of 14.5 million tons; and the area of corn is $1300.10,000 \mathrm{mu}$, with a total output of 5 million tons; soybean area of 12.5 million mu, with a total output of 1.3 million tons. The vegetable area is 14.18 million mu, with a total output of 28.92 million tons. Abundant agricultural products resources not only meet the needs of the province, but also occupy a certain share in the domestic and foreign markets. Some specialty agricultural products are welcomed by consumers in the international market. Anhui is also a major animal husbandry province in the country. In 2017, the province's total output of meat, eggs and milk reached 5.744 million tons, of which 3.963 million tons of meat, 1.462 million tons of eggs, and 319,000 tons of milk; the output value was 128.57 billion yuan, accounting for $27.2 \%$ of the total agricultural output value. The total production of meat, eggs, and milk and the number of poultry and pigs for slaughter rank 11 th, 6 th and 11th in the country. There are 44 livestock and poultry breed resources in the whole province, and 5 breeds including Wanxi white goose, Huai pig, Anqing Liubai pig, Wannan black pig and Zhongfeng are included in the national protection list. The province has 21 large counties with national live pig transfers, a total of 652 ministerial and provincial-level livestock and poultry breeding standardization demonstrations have been established, and the proportion of large-scale livestock and poultry breeding has reached $57.4 \%$. Anhui is also a major producer of freshwater aquatic products in China. The total area of inland waters such as ponds, lakes, reservoirs, rivers and rice fields ranks second in the country. In 2017, the total aquatic product output reached 2.4 million tons, ranking fourth in inland provinces. The province has 57 cities and counties with an annual output of more than 10,000 tons of aquatic products. In recent years, through the promotion of ecological and healthy breeding and adjustment and optimization of the species structure, the comprehensive production capacity of shrimp, crab, mandarin fish, turtle, loach, rice eel, and lake and reservoir organic fish has basically ranked among the top five in the country. The aquatic product farming area has expanded to 4.6 million mu, and the comprehensive planting and breeding area of rice and fishery in the province has reached $900000 \mathrm{mu}$.

According to the website of the Department of Agriculture of Anhui Province, the province's fertilizer use and pesticide use have achieved negative growth for three consecutive years; the fertilizer utilization rate and the pesticide utilization rate reached $37.6 \%$ and $39.6 \%$, respectively. The province organized the implementation of the "zero growth" action of chemical fertilizer use. The province's chemical fertilizer use decreased from 3.414 million tons in 2014 to 2.987 million 
tons in 2019 , an average annual decline of $2.6 \%$, achieving five consecutive declines; average per mu (planting area) fertilization was reduced from 25.1 to $21.8 \mathrm{~kg}$, and the fertilizer utilization rate of main crops increased from 34.4 to more than $39 \%$. The use of pesticides in the province has decreased from a maximum of 118,000 tons in 2013 to 88,000 tons in 2019 , with an average annual decrease of $4.8 \%$, achieving six consecutive declines. The unit use (per hectare of sown area) has been reduced from 12.3 to $9.3 \mathrm{~kg}$. The utilization rate of pesticides increased from $36.8 \%$ in 2015 to $41 \%$, and the coverage rates of green prevention and control and unified prevention and governance increased to $38.2 \%$ and $44.4 \%$ respectively. Through the statistical information website, we checked the comprehensive economic rankings, per capita income, agricultural and animal husbandry production scales of the counties in Anhui Province (see the first 3 rows of Table 2), and selected 10 typical counties and cities to which they belonged to conduct research.

\section{Materials and methods}

\section{Methodology}

\section{Selection of evaluation index system}

First of all, we consulted the relevant information on the safety of edible agricultural products, and visited the supervisors of several agricultural markets near our unit, so as to have a preliminary understanding of the main problems existing in China's edible agricultural products and the general situation of food supervision in the market. Then, we paid a special visit to Zhou GH, Professor of School of Food Science and Technology of Nanjing Agricultural University and Academician of International Academy of Food Science and Technology (IAFoST); Professor Li JC, College of Agriculture, Anhui Agricultural University; Professor Gu HY, director of Institute of Rural Economy, Shanghai Jiaotong University; and Professor Kong XZ, School of Agriculture and Rural Development, Renmin University of China. We have listened carefully to their guiding opinions: The developed countries have done a good job in food safety, and the implementation standards are relatively high, which is worthy of our learning, but we should mainly consider China's national conditions. At present, China's agricultural production mode is still relatively traditional, and the application intensity of chemical fertilizers and pesticides is generally high. The evaluation of food safety should not only ensure people's health, but also combine with the overall level that China can achieve. The established index system mainly includes the food that has been tested by the state, and also conforms to the actual situation of the region. After repeated discussions and multiple rounds of screening, our research group finally selected the following 24 kinds of edible agricultural products with prominent harmful residues, which were classified into 6 categories, and established the evaluation index system shown in Table 1. In determining the weight of indicators, we invited Zhou GH and other four experts as special experts (see the "Determine the weight of each index" section), and our indicator system was also recognized by them.

Green vegetables include cabbage, celery and other vegetables with leaves as food materials. In addition to winter, green vegetables are easy to grow insects, usually with heavy pesticide application. Cucumber, towel gourd and tomato in addition to the intensity of pesticide application, there are also operators of illegal spraying ripening agent. Shuifa food includes dried agaric, dried tremella, and dried vegetables. Some operators in order to shoddy, using toxic drugs on the quality of very poor water hair food "make-up", so often it contains high formaldehyde. Pesticide residues and ripening agents are mainly detected in fruits, especially strawberries, bananas, apples and oranges. Pork mainly detected clenbuterol; poultry mainly detected excessive antibiotics. For poultry eggs, regulators mainly detect whether poultry have been injected with toxic colorants, and use cultured eggs to pass off as wild ones. Cattle and sheep mainly eat grass, generally not easy to get sick, rarely feed antibiotics, cattle and mutton rarely have problems, so they are not included. At present, there are many problems in crucian carp and silver carp. The main problems are that farmers overfeed antibiotics, and kerosene and copper sulfate are used to keep the fish alive for a long time in the process of transportation and marketing. Monopterus albus and Misgurnus anguillicaudatus were mainly tested whether they were fed with hormone. Bean sprout is mainly used to detect whether it has been sprayed with growth-promoting drugs, while tofu and dried bean are mainly used to detect toxic additives. Frozen meat and hairtail belong to cold chain food, mainly testing whether there is processed "zombie meat", or spray formaldehyde to keep fresh.

\section{Determine the weight of each index}

To determine the index weight, the common methods are "Delphi" method, "Entropy weight" method, and "AHP" method. Delphi method was initiated by Helm O and Darke N in 1940s, and further developed by Golden T and Rand C. The essence of Delphi law is to concentrate the knowledge and experience of experts. Then, this method has been widely used, such as Wagale and Singh 2019) applied adaptive neural fuzzy inference system and fuzzy comprehensive evaluation model to evaluate the social and economic impact of rural highway construction. Delphi method is used to determine the weight of each index. Main characteristics of Delphi method as the following: (1) each expert makes decisions 
Table 1 Risk assessment index system of pesticide residues in edible agricultural products

Level I indicators and Level II indicators weights
Indicator weight

$\begin{array}{lll}\text { AHP } & \begin{array}{l}\text { Entropy Combined } \\ \text { weight }\end{array} & \begin{array}{l}\text { Entropy Combined } \\ \text { weight }\end{array}\end{array}$

(1)

(2)

\begin{tabular}{|c|c|c|c|c|c|c|c|c|}
\hline$B_{1}$ & $C_{11}$ Rice & 0.3602 & 0.1531 & 0.2981 & 0.1205 & 0.2884 & 0.0372 & 0.2633 \\
\hline \multirow{2}{*}{$\begin{array}{l}\text { Grain } \\
(0.262)\end{array}$} & $C_{12}$ Noodle & 0.3834 & 0.3488 & 0.3730 & 0.0862 & 0.2942 & 0.1773 & 0.3216 \\
\hline & $C_{13}$ Corn & 0.2564 & 0.4981 & 0.3289 & 0.7933 & 0.4174 & 0.7855 & 0.4151 \\
\hline \multirow{5}{*}{$\begin{array}{l}B_{2} \\
\text { Vegetables } \\
(0.184)\end{array}$} & $C_{21}$ Green vegetables & 0.2131 & 0.2562 & 0.2260 & 0.0862 & 0.1752 & 0.0924 & 0.1771 \\
\hline & $C_{22}$ Cucumber & 0.1903 & 0.1773 & 0.1864 & 0.1973 & 0.1824 & 0.3051 & 0.2248 \\
\hline & $C_{23}$ Tomatoes & 0.2035 & 0.1072 & 0.1746 & 0.1331 & 0.2312 & 0.1301 & 0.1818 \\
\hline & $C_{24}$ Towel gourd & 0.1832 & 0.3187 & 0.2237 & 0.3599 & 0.2102 & 0.2112 & 0.1917 \\
\hline & $C_{25}$ Shuifa food & 0.2089 & 0.1404 & 0.1883 & 0.2235 & 0.201 & 0.2612 & 0.2246 \\
\hline \multirow{4}{*}{$\begin{array}{l}B_{3} \\
\text { Fruits } \\
(0.120)\end{array}$} & $C_{31}$ Strawberry & 0.2819 & 0.5270 & 0.3554 & $*$ & $*$ & $*$ & $*$ \\
\hline & $C_{32}$ Banana & 0.2651 & 0.1424 & 0.2283 & $*$ & $*$ & $*$ & $*$ \\
\hline & $C_{33}$ Apple & 0.2079 & 0.1594 & 0.1934 & $*$ & $*$ & $*$ & $*$ \\
\hline & $C_{34}$ Orange & 0.2451 & 0.1712 & 0.2229 & $*$ & $*$ & $*$ & $*$ \\
\hline \multirow{5}{*}{$\begin{array}{l}B_{4} \\
\text { Meat, eggs } \\
(0.218)\end{array}$} & $C_{41}$ Pork & 0.2101 & 0.0644 & 0.1664 & 0.1328 & 0.1869 & 0.0988 & 0.1767 \\
\hline & $C_{42}$ Chicken & 0.2210 & 0.0256 & 0.1624 & 0.1846 & 0.2101 & 0.2699 & 0.2357 \\
\hline & $C_{43}$ Duck meat & 0.2205 & 0.0100 & 0.1574 & 0.1821 & 0.2090 & 0.1333 & 0.1943 \\
\hline & $C_{44}$ Poultry eggs & 0.1603 & 0.1084 & 0.1447 & 0.2031 & 0.1731 & 0.1305 & 0.1514 \\
\hline & $C_{45}$ Frozen meat & 0.1881 & 0.7916 & 0.3691 & 0.2974 & 0.2209 & 0.3675 & 0.2419 \\
\hline \multirow{4}{*}{$\begin{array}{l}B_{5} \\
\text { Aquatic products } \\
(0.142)\end{array}$} & $C_{51}$ Crucian carp & 0.2556 & 0.9726 & 0.4707 & 0.2793 & 0.2627 & 0.2412 & 0.2512 \\
\hline & $C_{52}$ Silver carp & 0.2712 & 0.0025 & 0.1906 & 0.4915 & 0.3372 & 0.4371 & 0.3210 \\
\hline & $\begin{array}{l}C_{53} \text { Monopterus albus, } \\
\text { loach }\end{array}$ & 0.2086 & 0.0046 & 0.1474 & 0.1375 & 0.1874 & 0.2319 & 0.2156 \\
\hline & $C_{54}$ Hairtail & 0.2646 & 0.0203 & 0.1913 & 0.0917 & 0.2127 & 0.0898 & 0.2122 \\
\hline \multirow{3}{*}{$\begin{array}{l}B_{6} \\
\text { Bean products } \\
(0.074)\end{array}$} & $C_{61}$ Bean sprouts & 0.4202 & 0.9974 & 0.5933 & 0.2453 & 0.3677 & 0.3296 & 0.3930 \\
\hline & $C_{62}$ Bean curd & 0.3602 & 0.0005 & 0.2523 & 0.4249 & 0.3796 & 0.3626 & 0.3609 \\
\hline & $C_{63}$ Dried tofu & 0.2196 & 0.0021 & 0.1544 & 0.3298 & 0.2527 & 0.3078 & 0.2461 \\
\hline
\end{tabular}

Where Combined average $(\mathrm{i})=0.7 \mathrm{AHP}+0.3$ Entropy weight $(i)=1,2,3$

independently and is not influenced by other experts; (2) each expert directly gives weight to each evaluation index based on experience, without the help of mathematical model; (3) it does not need complex calculation to synthesize experts' opinions, and it directly calculates the average and variance of the results given by experts. And the comprehensive results are anonymously fed back to the experts, so that the experts can independently give each index weight again after thinking. Generally, it needs to repeat several rounds until the variance is very small. For the weight of level I indicators $B_{1}, B_{2} \cdots B_{6}$, we use the "Delphi" method. We have set up a 7-member expert group, including 4 external experts (Zhou GH, Li JC, $\mathrm{Gu}$ HY and Kong XZ), 3 professors and doctors of our research group. Let each expert independently give the weight of indicators $B_{1}, B_{2} \cdots B_{6}$, and then, the comprehensive results are fed back to each expert. A total of three rounds were repeated. The final results are shown in
Table 1. The weight of level II indicators is relative to level I indicators. We first use Entropy weight method and AHP method, take the average value of the two, and then use mathematical software to calculate, with the results listed in Table 1.

Situation 1 . The steps of weight calculation by entropy weight method

"Entropy" is a measure reflecting the disorder degree of system in information theory. Entropy can be used to judge the dispersion degree of an index. In many comprehensive evaluation problems, people use the entropy value of the index to determine the weight (Fan et al. 2012). For example, we find the weight of level II indicators $C_{h 1}, C_{h 2} \cdots C_{h n}$, with respect to level I indicator $B_{h}$, and denote it as $B_{h}\left(C_{h}\right)=$ $\left(w_{i}^{h}, w_{2}^{h}, \cdots w_{n}^{h}\right) h=1,2, \cdots 6$. Suppose that the standardized 
index value of index $C_{h i}(i=1,2, \cdots, n)$ in the $j$-th participating unit is $\bar{C}_{h i}(j)(j=1,2, \cdots, m)$

(i) Unitization of vector $\left(\bar{C}_{h i},(1), \bar{C}_{h i},(2), \cdots \bar{C}_{h i},(m)\right)$ That is to calculate the $P_{i j}$ of $\bar{C}_{h i},(j)$ 's specific gravity in the $C_{h i}$

$P_{i j}=C_{h i},(j) / \sum_{j=1}^{m} C_{h i},(j)$

(ii) Calculate the entropy $e_{i}$, of the indicator $C_{h i}$

$e_{i},=-k \sum_{j=1}^{m} \ln P_{i j}, k=1 / \ln m, e_{i} \in[0,1]$

(iii) Calculate difference coefficient $\mathrm{g}_{i}$ of indicator $C_{h 1}$

$\mathrm{g}_{i}=1-e_{i}$,

The greater the difference between indicator values $\bar{C}_{h i},(1)$ $, \bar{C}_{h i},(2), \cdots \bar{C}_{h i},(m)$ the smaller the entropy $e_{i}$ of indicator $C_{h i}$ and the greater the difference coefficient of indicator $C_{h i}$ is.

(iv) The weights of each indicator can be obtained by normalizing the coefficient of difference:

$w_{i}^{h}=\mathrm{g}_{i} / \sum_{i=1}^{n} \mathrm{~g}_{i}(i=1,2, \cdots, n)$

Because entropy calculation needs to use the specific distribution of indicators, Entropy weight (1), Entropy weight (2) and Entropy weight (3) in Table 1 are calculated according to the data in Table 3, Table 5 and Table 7 respectively.

Situation 2. The steps of AHP method for weight calculation

Analytic Hierarchy Process (AHP) method was proposed by Professor Saaty $\mathrm{T}$ of the University of Pittsburgh, an American operations researcher, in the early 1970s. It is used to determine the weight of multiple the lower level indicators on the upper level indicators (Riccardo et al. 2013). It does not need to use the specific statistical data of each indicator, but is completely made according to the judgment made by experts independently based on their experience, and then determine the weight of each index through a series of calculations. Using the seven-member expert group established by us, the AHP weights of all level II indicators relative to level I indicators are calculated according to the following methods. The results are shown in the AHP in Table 3. In general, let's find the weight of level II indicators $C_{h 1}, C_{h 2}, \cdots, C_{h n}$ with respect to level I indicator $B_{h}$, and record it as $B_{h}\left(C_{h}\right)=$ $\left(w_{1}^{h}, w_{2}^{h}, \cdots, w_{n}^{h}\right)(h=1,2,3,4)$. (i) Ask each expert in the expert group to compare the importance of each pair of indicators $C_{1 i}, C_{1 j}(i, j=1,2, \cdots, n)$, and construct a positive reciprocal judgment matrix. Let the matrix constructed by the $k$-th expert be as follows:

$R(k)=\left[\begin{array}{cccc}u_{11}^{(k)} & u_{12}^{(k)} & \cdots & u_{1 n}^{(k)} \\ u_{21}^{(k)} & u_{22}^{(k)} & \cdots & u_{2 n}^{(k)} \\ \cdots & \cdots & \cdots & \cdots \\ u_{n 1}^{(k)} & u_{n 2}^{(k)} & \cdots & u_{n n}^{(k)}\end{array}\right], k=1,2, \cdots, 7$.

where $u_{i j}^{(k)}$ indicates that the $k$-th expert considers the degree of importance of indicator $C_{h i}$ relative to indicator $C_{h j}$, their values are taken from $\frac{1}{9}, \frac{1}{8}, \cdots, \frac{1}{2}, 1,2, \cdots, 9$. Obviously, $u_{i j}^{(k)}=1 / u_{j i}^{(k)}, u_{i i}^{(k)}=1$. Noting $\bar{u}_{i j}=\sqrt[7]{\prod_{k=1}^{7} u_{i j}^{(k)}}$ $(i, j=1,2, \cdots, n)$, it is easy to prove that

$\bar{R}=\left[\begin{array}{c}\bar{u}_{11} \bar{u}_{12} \cdots \bar{u}_{1 n} \\ \bar{u}_{21} \bar{u}_{22} \cdots \bar{u}_{2 n} \\ \cdots \cdots \cdots \cdots \\ \bar{u}_{n 1} \bar{u}_{n 2} \cdots \bar{u}_{n n}\end{array}\right]$,

is still a positive reciprocal matrix, and satisfies $\bar{u}_{i i}=1, \bar{u}_{i j}=1 / \bar{u}_{j i}>0$.

(ii) Check the consistency of the positive reciprocal matrix $\bar{R}$ . We calculate the maximum eigenvalue $\lambda_{n}$ of the $\bar{R}$ and the value of the indicator $C R=C I / R I$, where $C I=\left(\lambda_{n}-\right.$ $n) /(n-1)$. There is a fixed corresponding relationship between the value of $R I$ and the order of $\bar{R}$, which is given in Table 2 (Riccardo et al. 2013).

When $C R<0.1$, it is considered satisfactory (otherwise reconstruct $R(k)$ and $R$ ).

(iii) The characteristic vector $\bar{a}=\left(\bar{a}_{1}, \bar{a}_{2}, \cdots, \bar{a}_{n}\right)$ of matrix $\bar{R}$ corresponding to the $\lambda_{n}$ is calculated with a simple method, where $\bar{a}_{i}=\sqrt[n]{\prod_{j=1}^{n} \bar{u}_{i j}}, i=1,2, \cdots, n$. By uniting the vector $\bar{a}$, we can get $B_{h}\left(C_{h}\right)=$ $\left(w_{1}^{h}, w_{2}^{h}, \cdots, w_{n}^{h}\right)$, where $w_{i}^{h}=\bar{a}_{i} / \sum_{i=1}^{n} \bar{a}_{i}$.

Table 2 The corresponding relationship between the value of $R$ Iand the order of $\bar{R}$

\begin{tabular}{llllllll}
\hline$n$ & 3 & 4 & 5 & 6 & 7 & 8 & 9 \\
\hline RI & 0.58 & 0.90 & 1.12 & 1.24 & 1.32 & 10.4 & 1.45 \\
\hline
\end{tabular}


For example, we find the weight of the index $C_{21}, C_{22}, \cdots$, $C_{25}$ for the index $B_{2}$. We synthesize the judgment matrix given by seven experts and get

$$
\begin{aligned}
\bar{R} & =\left[\begin{array}{ccccc}
1 & 1.1198 & 1.0472 & 1.1632 & 1.0201 \\
0.8930 & 1 & 0.9351 & 1.3876 & 0.9110 \\
0.9550 & 1.0694 & 1 & 1.1108 & 0.9742 \\
0.8597 & 0.9627 & 0.9002 & 1 & 0.8770 \\
0.9829 & 1.0977 & 1.0265 & 1.1403 & 1
\end{array}\right], \lambda_{5} \\
& =5.06682, C R=0.01492 .
\end{aligned}
$$

Because the $\bar{R}$ is more satisfactory, we get

$$
\begin{aligned}
B_{2}\left(C_{2}\right) & =\left(w_{1}^{2}, w_{2}^{2}, \cdots, w_{5}^{2}\right) \\
& =(0.2131,0.1903,0.2035,0.1832,0.2089) .
\end{aligned}
$$

The characteristic of entropy weight method is that it makes full use of the entropy of index to determine the weight, which seems to be more objective. In fact, this method also has limitations, no matter whether the index is important or not, as long as the index value difference is large, the entropy is small, and the corresponding weight is large, which is mainly suitable for evaluating the differences between different evaluation units. For example, in the five level II indicators of the level I indicator $B_{5}$, for indicator $C_{51}$, the Entropy weight (1) calculated according to the data in Table 3 is 0.9726 , and the Entropy weight (2) calculated according to the data in Table 5 is 0.2793 . For indicator $\mathrm{C}_{52}$, we calculated Entropy weight (1) as 0.0025 and Entropy weight (2) as 0.4915. This is obviously not very reasonable (see Table 1 ).

AHP method is only based on the importance of each indicator, which is mainly suitable for evaluating the degree of reaching the standard of the participating units. The main basis of this evaluation should be the importance of all kinds of edible agricultural products in the total food consumption, taking into account the differences in the quality of edible agricultural products in different cities and counties. So the weight of the level II indicator is determined by the combination of entropy weight method and AHP method. And in combination weight, entropy weight only accounts for 0.3 , while AHP weight accounts for 0.7

\section{Two-level comprehensive fuzzy evaluation method}

Fuzzy set theory was put forward by American automatic control expert Professor Zadeh L in 1965 to express the uncertainty of things. In recent decades, the operation of fuzzy sets, the theory and application of fuzzy comprehensive evaluation have developed rapidly. For example, Wagale et al. (2019) applied fuzzy comprehensive evaluation model to evaluate the social and economic impact of rural highway construction. If we divide the degree of harmful substances in edible agricultural food into several grades, the boundary of these grades must be fuzzy, and it is suitable to use the twolevel fuzzy comprehensive evaluation model to evaluate them. Generally, the total indicator $\overline{\bar{B}}$ of evaluation object involves $m$ level I indicators $B_{1}, B_{2}, \cdots, B_{m}$, and their weight vector is $a=\left(w_{1}, w_{2}, \cdots, w_{m}\right)$. Indicator $B_{i}(i=1,2, \cdots, m)$ includes $m_{i}$ level II indicators $C_{i 1}, C_{i 2}, \cdots, C_{i m_{i}}$, and their weight vector about indicator $B_{i}$ is: $b_{i}=\left(v_{i 1}, v_{i 2}, \cdots, v_{i n_{i}}\right)$. The quality of all indicators was divided into $n$ grades: $A_{1}, A_{2}, \cdots, A_{n}$. The membership function of indicator $C_{i j}(i=1,2, \cdots, m, j=1,2$, $\left.\cdots, m_{i}\right)$ is:

$\widetilde{C}_{i j} \rightarrow r_{i j 1} / A_{1}+r_{i j 2} / A_{2}+\cdots+r_{i j n} / A_{n}=\left(r_{i j 1}, r_{i j 2}, \cdots, r_{i j n}\right)$.

Let $\quad R_{i}=\left[\begin{array}{cccc}r_{i 11} & r_{i 12} & \cdots & r_{i 1 n} \\ r_{i 21} & r_{i 22} & \cdots & r_{i 2 n} \\ \cdots & \cdots & \cdots & \cdots \\ r_{i m_{i} 1} & r_{i m_{i} 2} & \cdots & r_{i m_{i} n}\end{array}\right],(i=1,2, \cdots, m)$

be the fuzzy evaluation matrix of indicator $B_{i}$.

First level evaluation: The fuzzy evaluation results of indicator $B_{i}(i=1,2, \cdots, m)$ were as follows

$\widetilde{r}_{i}=b_{i} \circ R_{i}$

$$
\begin{aligned}
& =\left(v_{i 1}, v_{i 2}, \cdots, v_{i m_{i}}\right) \circ\left[\begin{array}{cccc}
r_{i 11} & r_{i 12} & \cdots & r_{i 1 n} \\
r_{i 21} & r_{i 22} & \cdots & r_{i 2 n} \\
\cdots & \cdots & \cdots & \cdots \\
r_{i m_{i} 1} & r_{i m_{i} 2} & \cdots & r_{i m_{i} n}
\end{array}\right] \\
& =\left(s_{i 1}, s_{i 2}, \cdots, s_{i n}\right) .
\end{aligned}
$$

where

$$
\begin{aligned}
s_{i k} & =\left(v_{i 1}, v_{i 2}, \cdots, v_{i m_{i}}\right) \circ\left[\begin{array}{c}
r_{i 1 k} \\
r_{i 2 k} \\
\vdots \\
r_{i m_{i} k}
\end{array}\right] \\
& =\left(v_{i 1} \wedge r_{i 1 k}\right) \vee\left(v_{i 2} \wedge r_{i 2 k}\right) \vee \cdots \vee\left(v_{i m_{i}} \wedge r_{i m_{i} k}\right), k=1,2, \cdots n .
\end{aligned}
$$

The " $\wedge$ " is the symbol of multiplication of fuzzy numbers, which means to take the minimum value; the " $\mathrm{V}$ " is the sign of fuzzy number addition, which means to take the maximum value.

Let $R=\left[\begin{array}{cccc}s_{11} & s_{12} & \cdots & s_{1 n} \\ s_{21} & s_{21} & \cdots & s_{2 n} \\ \cdots & \cdots & \cdots & \cdots \\ s_{m 1} & s_{m 2} & \cdots & s_{m n}\end{array}\right]$,

be total fuzzy evaluation matrix. If the maximum value in the $i$ th row of the matrix $R$ first appears in the $j$-th column, then the quality of the factor $B_{i}$ is evaluated as $A_{j}$ (try to give good comments). 
Table 3 Food pesticide residue compliance in some farmers' markets in 10 cities (\%)

\begin{tabular}{|c|c|c|c|c|c|c|c|c|c|c|}
\hline & Hefei & Huaibei & Fuyang & Tongling & Wuhu & Ma'anshan & Anqing & Chuzhou & Lu'an & Xuancheng \\
\hline$C_{11}$ & 98.81 & 98.05 & 98.65 & 97.42 & 97.91 & 97.83 & 98.21 & 98.63 & 98.71 & 98.72 \\
\hline$C_{12}$ & 96.21 & 96.90 & 96.23. & 97.02 & 96.26 & 97.10 & 95.68 & 95.21 & 95.42 & 95.25 \\
\hline$C_{13}$ & 83.61 & 86.12 & 87.72 & 84.03 & 84.12 & 83.37 & 85.30 & 85.27 & 84.30 & 85.02 \\
\hline$C_{21}$ & 82.14 & 83.01 & 81.25 & 82.34 & 82.15 & 84.03 & 82.05 & 83.14 & 83.07 & 82.51 \\
\hline$C_{22}$ & 87.51 & 86.30 & 87.25 & 86.03 & 86.21 & 85.23 & 86.24 & 87.10 & 86.31 & 86.24 \\
\hline$C_{23}$ & 85.12 & 85.13 & 84.41 & 85.07 & 84.26 & 84.42 & 84.36 & 85.07 & 84.21 & 83.62 \\
\hline$C_{24}$ & 86.31 & 86.43 & 85.47 & 85.30 & 87.01 & 87.12 & 84.26 & 86.23 & 85.37 & 86.61 \\
\hline$C_{25}$ & 85.40 & 85.12 & 86.03 & 84.68 & 85.62 & 84.16 & 84.23 & 85.06 & 85.10 & 85.34 \\
\hline$C_{31}$ & 96.03 & 96.24 & 95.83 & 96.61 & 96.45 & 95.36 & 96.14 & 96.23 & 95.72 & 95.40 \\
\hline$C_{32}$ & 97.24 & 97.25 & 96.83 & 96.57 & 97.02 & 97.25 & 96.94 & 97.02 & 97.21 & 96.97 \\
\hline$C_{33}$ & 98.63 & 98.27 & 97.98 & 98.31 & 98.52 & 98.41 & 98.43 & 98.05 & 97.98 & 98.52 \\
\hline$C_{34}$ & 98.20 & 98.12 & 98.31 & 97.86 & 97.59 & 98.06 & 98.13 & 97.84 & 97.60 & 97.95 \\
\hline$C_{41}$ & 98.62 & 98.81 & 98.54 & 98.20 & 98.32 & 98.16 & 98.42 & 98.26 & 98.20 & 98.35 \\
\hline$C_{42}$ & 98.01 & 98.12 & 98.43 & 98.10 & 98.31 & 98.22 & 98.05 & 98.12 & 98.31 & 98.14 \\
\hline$C_{43}$ & 98.12 & 98.10 & 98.22 & 98.13 & 98.12 & 98.01 & 98.23 & 98.21 & 98.03 & 98.02 \\
\hline$C_{44}$ & 98.85 & 98.61 & 98.15 & 98.13 & 98.20 & 98.11 & 98.14 & 98.02 & 98.10 & 98.02 \\
\hline$C_{45}$ & 89.92 & 90.21 & 90.35 & 89.84 & 88.50 & 88.97 & 88.74 & 89.02 & 89.21 & 90.12 \\
\hline$C_{51}$ & 98.71 & 98.35 & 98.24 & 98.63 & 98.20 & 98.01 & 98.15 & 98.31 & 87.63 & 88.25 \\
\hline$C_{52}$ & 98.65 & 98.23 & 98.21 & 98.22 & 97.90 & 98.11 & 98.30 & 98.07 & 98.15 & 97.82 \\
\hline$C_{53}$ & 97.13 & 98.03 & 98.10 & 97.92 & 98.03 & 97.95 & 98.14 & 97.52 & 97.83 & 97.91 \\
\hline$C_{54}$ & 89.57 & 89.63 & 88.67 & 89.01 & 87.62 & 88.41 & 89.02 & 89.23 & 88.67 & 88.62 \\
\hline$C_{61}$ & 98.63 & 98.51 & 98.20 & 98.41 & 88.16 & 89.02 & 89.06 & 88.63 & 88.74 & 89.12 \\
\hline$C_{62}$ & 98.21 & 98.16 & 98.03 & 98.22 & 97.92 & 98.24 & 98.05 & 98.13 & 98.14 & 98.30 \\
\hline$C_{63}$ & 98.61 & 98.42 & 98.23 & 98.31 & 98.11 & 98.24 & 98.80 & 98.12 & 98.05 & 98.14 \\
\hline
\end{tabular}

Second level evaluation: The fuzzy evaluation result of the total indicator $\overline{\bar{B}}$ of the evaluation object is

$$
\begin{aligned}
a \circ R & =\left(w_{1}, w_{2}, \cdots, w_{m}\right) \circ\left[\begin{array}{cccc}
s_{11} & s_{12} & \cdots & s_{1 n} \\
s_{21} & s_{21} & \cdots & s_{2 n} \\
\cdots & \cdots & \cdots & \cdots \\
s_{m 1} & s_{m 2} & \cdots & s_{m n}
\end{array}\right] \\
& =\left(t_{1}, t_{2}, \cdots, t_{n}\right) .
\end{aligned}
$$

If the maximum component of the vector $\left(t_{1}, t_{2}, \cdots, t_{n}\right)$ first appears in the $j$-th column, the total evaluation level of the evaluation object is determined as $A_{j}$. In addition, we calculate

$$
\begin{aligned}
\widetilde{S}_{i} & =\left(s_{i 1}+s_{i 2}+\cdots+s_{i j}\right) /\left(s_{i 1}+s_{i 2}+\cdots+s_{\text {in }}\right), \widetilde{S}_{T} \\
& =\left(t_{1}+t_{2}+\cdots+t_{j}\right) /\left(t_{1}+t_{2}+\cdots+t_{n}\right) .
\end{aligned}
$$

$\widetilde{S}_{i}$ and $\widetilde{S}_{T}$ respectively indicate that the quality of indicator $B_{i}(i=1,2, \cdots, 6)$ and comprehensive indicator $\overline{\bar{B}}$ is considered not lower than the total membership of $A_{j}$. That is to say, among all the respondents, the proportion of those who think that the grade of the evaluation object is not lower than $A_{j}$ (see the "Investigation on the production and consumption of edible agricultural products in 10 counties" section for specific examples).

\section{Damage-abatement production function with pesticide as a factor}

The output of agricultural products mainly depends on the input of fertilizer (expressed by $x_{1}$ ) and labor (including comprehensive labor input, expressed by $x_{2}$ ). Other rigid factors such as seed, irrigation and machine tillage do not need to be included in the model. Therefore, yield is generally reflected by $C-D$ production function $y=a x_{1}^{\beta_{1}} x_{2}^{\beta_{2}}$. The pursuit of economic benefits is the fundamental purpose of farmers engaged in agricultural production. Pesticides cannot directly promote the growth of crops and produce value, but can indirectly produce value by reducing diseases, insects and weeds and avoiding the reduction of crop production. The behavior of farmers applying pesticides is a kind of production investment. The basic starting point is to do their best and make use of the scientific and technological conditions at that time, and strive to recover the losses of agricultural products caused by 
diseases, insects and weeds to the greatest extent with the minimum pesticide investment. Hall and Norgaard (1973) and Talpaz and Borosh (1974) creatively proposed that pesticide is also a factor of production, and based on this, Damageabatement production function model was constructed. A three-dimensional yield description system including fertilizer, labor and pesticide was formed. In 1995, Fox and Weersink made a summary and comparison of the specific forms of Damage-abatement production function.

According to the research results of Shen (2011), herbicides mainly pollute the land, destroy the biota in the land, and affect the growth of crops. If applied correctly, especially in the early stage of crop growth, the impact on human and livestock is very small. Therefore, this paper mainly considers insecticides and sets the maximum degree of crop yield reduction caused by insect disaster as $(i=1,2, \cdots, 13)$ If the pesticide input per mu of crops is $T$, the pest damage can be reduced by $C(T)$, with $d C(T) / d T>$ 0 , and when $T=0, C(T)=0$. Therefore, when the pesticide cost of pest control is input per mu, the actual yield of each mu of crop becomes

$y=a x_{1}^{\beta_{1}} x_{2}^{\beta_{2}}(1-\delta)+\delta a x_{1}^{\beta_{1}} x_{2}^{\beta_{2}} C(T)$.

This formula is called Damage-abatement production function considering pesticide input. Scholars have different opinions on the specific form of $C(T)$, such as Parteo form, let $C(T)=1-(k / T)^{2}$; Exponential form, let $C(T)=1-$ $\exp (-m T)$; Weibull form, let $C(T)=1-\exp \left(-T^{m}\right)$.

\section{Collection and arrangement of data}

From July to August 2020, using the summer vacation of students to return home and combining social practice activities, we arranged 20 students living in Anhui and neighboring provinces, and conducted 8 weeks of investigation activities in 10 cities and 10 counties in Anhui Province. They were divided into five groups, each with a master's degree student in charge of the investigation of two cities and two counties. The overall framework of our research is shown in Fig. 1.

\section{Investigation on the quality of edible agricultural products consumed in 10 cities}

In Hefei and other 10 cities in Anhui Province, we investigated the "Smart Agricultural Trade Data Center" of 40 farmers' markets, 20 individual edible agricultural products stores, and student canteens of 40 schools. At present, only 14 pesticide residues were detected, including pesticide residues in vegetables and fruits. Meat essence "ractopamine" in meat. Malachite green in aquatic products. In other classes, formaldehyde and so on, and the implementation standard is relatively low. For example, the comprehensive inhibition rate $^{1}$ of pesticide residues is less than $50 \%$, and ractopamine is less than $0.5 \mathrm{hhp}$, it is considered qualified. After setting the detection type and the upper limit of pesticide residues, the rapid detection equipment only shows negative or positive, and does not show the specific degree of compliance. We checked the spot check records of each "Smart Agricultural Trade Data Center" in the last month, including the stalls, food names and index values of the items sampled every day. We can see that almost every market has some stalls selling ecological food, such as "running pork" (free range pigs without hormone), wild fish. Consumers say the quality is really good, but the price is at least $10 \%$ higher than other stalls, and the business is slightly better than other stalls. In order to reduce the random volatility of the sample data, for each city's 24 survey indicators, we counted the average compliance degree of the four "Smart Agricultural Trade Data Center" in each city in the last 30 days (see Table 3). Method: For example, for indicator $C_{11}$ first count the total number of times that indicator $C_{11}$ is inspected and the total number of times that indicator $C_{11}$ reaches the standard within 30 days in each market, calculate the average rate of reaching the standard within 30 days in each market, and then calculate the average rate $\bar{C}_{11}$ of reaching the standard in four markets.

Using Combined average (1) in Table 1, we calculate the average exceeding standard rate of 6 kinds of food pesticide residues in 10 urban farmers' markets, and finally calculate the comprehensive exceeding standard rate of 6 kinds of food pesticide residues (denoted by $\overline{\bar{B}}$ ), as shown in Table 4 .

At the same time, we investigated the food pesticide residues in four school canteens in each city. The government has strict supervision on school canteens, and the food and drug regulatory authorities in the jurisdiction usually inspect the school's food materials once a week. The unqualified food materials shall be destroyed immediately, and the Contractor shall explain the source and write down the rectification plan. Most school canteens have fixed food suppliers, and the phenomenon of excessive pesticide residues is lower than that in the market. Large-scale school management departments use self-purchased rapid detector to spot check the food materials of the canteen from time to time. We have checked the inspection records of the supervision department kept by each school in recent 1 year. For 20 survey indicators of school canteens (canteens do not operate fruits), we have counted the average compliance rate of four schools in each city in recent three months (see Table 5). The method is the same as that of the market average rate.

\footnotetext{
${ }^{1}$ Inhibition rate: under certain conditions, organophosphorus and carbamate pesticides can inhibit the normal function of cholinesterase, and the inhibition rate is positively correlated with the concentration of pesticides. By calculating the inhibition rate, we can judge whether there is a high dose of this kind of pesticide in the sample.
} 


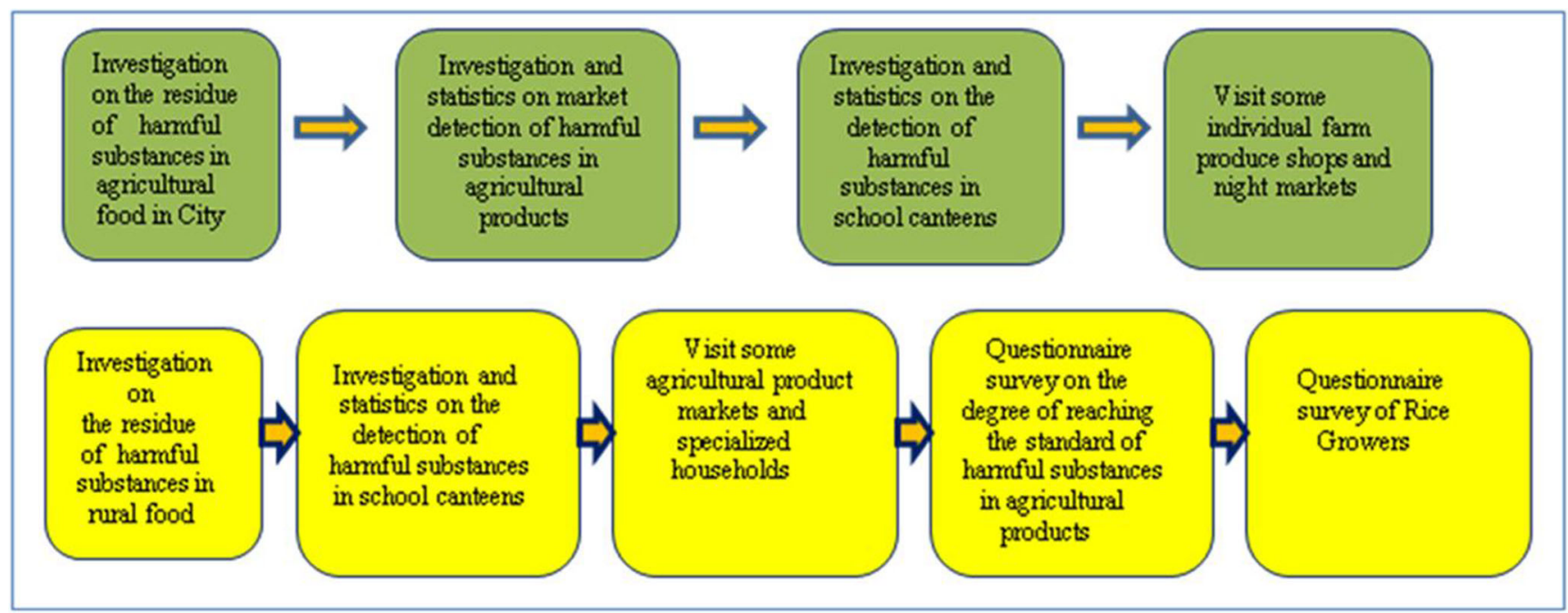

Fig. 1 Research framework on pollution control of edible agricultural products in Anhui Province

Using Combined average (2) in Table 1, we calculated the average exceeding standard rate of 5 categories of food pesticide residues in school canteens of 10 cities, and finally calculated the comprehensive exceeding standard rate of 5 categories of food pesticide residues, as shown in Table 6. When calculating the comprehensive exceeding standard rate, because the school canteen does not sell fruit, the weight of fruit 0.12 in Table 1 is allocated to the other five categories in proportion, and the weight of five categories of food is adjusted as follows: $0.2977,0.2091,0.2477,0.1614,0.0841$.

We also visited some individual farmers' food stores in each city, and the food regulatory authorities in the jurisdiction supervised these stores. The shopkeeper showed us the qualification records of some food spot checks, including the date and variety of spot checks. Sampling time is basically irregular, the interval is short 1 week, the longest 2 months. It is estimated that the owner will not introduce the unqualified situation of sampling inspection, so we do not count the food quality of individual stores. We also see that in the evening, there are some stalls on both sides of the streets near many residential areas, including those selling fruits, corn, vegetables and other agricultural products. The agricultural residues of these stalls are basically in a laissez faire state. However, the scale of agricultural products sold in individual stores and night markets is not large, and we estimate that it will not exceed $10 \%$ of the total amount of edible agricultural products consumed in cities, and individual stores are under the semi monitoring of the government. Therefore, it can be asserted that more than $95 \%$ of the edible agricultural products in cities are under government monitoring.

\section{Investigation on the production and consumption of edible agricultural products in 10 counties}

We chose another sample county from each sample city to conduct field research on the control of edible agricultural products in these counties. Distribution of sample counties: Suixi County and Linquan County in Huaibei plain; Zongyang County along the river plain, Wuwei County and Dangtu County; Feixi of Jianghuai hills, Taihu Lake and Fengyang County; Jinzhai County in Dabie Mountain Area in West Anhui Province and Jingxian County in southern Anhui Province. Suixi County has 11 towns, Linquan county has 23 towns, Zongyang County has 19 towns, no county has 21 towns, Dangtu County has 25 towns, Feixi County has 13 towns, Taihu County has 15 towns, Fengyang County has 17

Table 4 Classification and summary of food pesticide residue compliance rate in 10 cities (\%)

\begin{tabular}{|c|c|c|c|c|c|c|c|c|c|c|}
\hline & Hefei & Huaibei & Fuyang & Tongling & Wuhu & Ma'anshan & Anqing & Chuzhou & Lu'an & Xuancheng \\
\hline$B_{1}$ & 92.862 & 93.697 & 94.153 & 92.867 & 92.759 & 92.802 & 93.020 & 92.960 & 92.743 & 92.920 \\
\hline$B_{2}$ & 85.126 & 85.073 & 84.683 & 84.525 & 84.934 & 84.954 & 84.057 & 85.185 & 84.687 & 84.767 \\
\hline$B_{3}$ & 97.293 & 97.282 & 97.027 & 97.208 & 97.235 & 96.983 & 97.209 & 97.121 & 96.916 & 96.930 \\
\hline$B_{4}$ & 98.957 & 95.383 & 95.392 & 95.077 & 94.645 & 94.747 & 94.717 & 94.784 & 94.858 & 95.179 \\
\hline$B_{5}$ & 96.717 & 96.612 & 96.383 & 96.607 & 96.094 & 96.184 & 96.431 & 96.412 & 91.338 & 91.569 \\
\hline$\underline{B_{6}}$ & 98.521 & 98.408 & 98.162 & 98.347 & 92.159 & 92.770 & 92.832 & 92.492 & 92.549 & 92.829 \\
\hline $\bar{B}$ & 94.265 & 93.671 & 93.639 & 93.271 & 92.697 & 92.695 & 92.714 & 92.882 & 92.009 & 92.195 \\
\hline
\end{tabular}


Table 5 Average compliance rate of 20 indicators of school canteens in 10 cities (\%)

\begin{tabular}{|c|c|c|c|c|c|c|c|c|c|c|}
\hline & Hefei & Huaibei & Fuyang & Tongling & Wuhu & Ma'anshan & Anqing & Chuzhou & Lu'an & Xuancheng \\
\hline$C_{11}$ & 99.02 & 98.78 & 98.51 & 98.12 & 98.23 & 98.21 & 98.02 & 98.45 & 98.26 & 98.71 \\
\hline$C_{12}$ & 97.52 & 97.54 & 97.23. & 97.56 & 97.62 & 97.53 & 98.01 & 97.92 & 97.31 & 97.46 \\
\hline$C_{13}$ & 97.54 & 97.92 & 98.03 & 96.38 & 97.29 & 95.13 & 96.43 & 97.62 & 97.30 & 96.85 \\
\hline$C_{21}$ & 84.21 & 84.71 & 85.14 & 84.52 & 84.71 & 85.12 & 84.50 & 85.03 & 85.42 & 84.34 \\
\hline$C_{22}$ & 88.61 & 88.25 & 87.96 & 87.47 & 87.43 & 86.24 & 87.26 & 87.98 & 87.62 & 88.12 \\
\hline$C_{23}$ & 85.12 & 85.13 & 84.41 & 85.07 & 84.26 & 84.42 & 84.36 & 85.07 & 84.21 & 83.62 \\
\hline$C_{24}$ & 86.31 & 86.43 & 85.47 & 85.30 & 87.01 & 87.12 & 84.26 & 86.23 & 85.37 & 86.61 \\
\hline$C_{25}$ & 87.53 & 87.21 & 88.04 & 87.23 & 87.12 & 85.62 & 86.04 & 87.12 & 87.31 & 87.13 \\
\hline$C_{41}$ & 98.21 & 98.65 & 98.02 & 98.53 & 98.14 & 98.23 & 98.05 & 97.98 & 98.02 & 97.90 \\
\hline$C_{42}$ & 97.56 & 97.18 & 98.03 & 98.21 & 98.05 & 98.12 & 98.06 & 97.89 & 97.90 & 98.20 \\
\hline$C_{43}$ & 98.08 & 97.25 & 98.43 & 98.01 & 98.11 & 97.95 & 97.62 & 98.12 & 97.91 & 97.86 \\
\hline$C_{44}$ & 99.00 & 98.91 & 98.36 & 98.65 & 98.71 & 98.23 & 98.24 & 98.32 & 98.14 & 97.95 \\
\hline$C_{45}$ & 96.41 & 97.12 & 97.31 & 96.82 & 96.13 & 96.51 & 96.33 & 97.10 & 97.24 & 97.26 \\
\hline$C_{51}$ & 97.40 & 97.21 & 97.04 & 96.85 & 96.43 & 97.20 & 96.35 & 97.85 & 97.52 & 97.41 \\
\hline$C_{52}$ & 96.62 & 96.38 & 97.05 & 97.21 & 96.27 & 98.52 & 96.43 & 96.81 & 97.13 & 96.52 \\
\hline$C_{53}$ & 95.21 & 95.20 & 94.82 & 95.31 & 94.74 & 94.51 & 95.01 & 95.21 & 94.78 & 94.63 \\
\hline$C_{54}$ & 97.05 & 97.42 & 96.75 & 96.81 & 97.13 & 96.85 & 96.92 & 97.03 & 97.12 & 97.01 \\
\hline$C_{61}$ & 98.26 & 98.21 & 98.13 & 98.22 & 98.10 & 97.91 & 98.05 & 98.11 & 98.23 & 97.86 \\
\hline$C_{62}$ & 98.41 & 98.31 & 98.84 & 98.15 & 98.07 & 98.45 & 98.41 & 97.92 & 98.00 & 98.22 \\
\hline$C_{63}$ & 98.23 & 98.32 & 98.21 & 98.24 & 98.24 & 98.12 & 98.22 & 97.91 & 97.95 & 97.65 \\
\hline
\end{tabular}

towns, Jinzhai County has 28 towns, Jing County has 30 towns. Among them, Feixi, Wuwei, Dangtu and Suixi are the first, fifth, sixth and tenth counties in Anhui Province; Taihu, Jing and Jinzhai are all in the bottom 10. We visited the Agricultural and Rural Bureau of the sample county to understand the proportion, type and organization form of the characteristic planting and breeding, professional cooperative production in the sample county. Each county visited 8-10 villages and towns, visited the township agricultural technology station, understood the local farmers' acceptance of technical guidance, and visited some ecological production bases. We focus on the investigation of four middle school canteens in each county, including a county middle school. Only the mountainous primary schools with a very scattered population, some students have a meal in the canteen at noon, and generally there is no student canteen in rural primary schools. Kindergartens are concentrated in the county and rural towns, and all kindergartens have canteens. The government and school leaders are very serious about the management of student canteens, and dare not be careless. Some large-scale schools often carry out self-examination. The food inspection of student canteens is carried out by the county Drug and Food Supervision Bureau, but the rural schools are scattered, junior middle schools only check once every two months, senior middle schools and kindergartens check once every month. We counted the inspection records of four school canteens in the last year, first calculated the compliance rate of 20 survey indicators of each school, and then calculated the average compliance rate of four schools (see Table 7).

Table 6 Classification and summary of average standard rate of 20 indicators in canteen of 10 cities (\%)

\begin{tabular}{lllllllllll}
\hline & Hefei & Huaibei & Fuyang & Tongling & Wuhu & Ma'anshan & Anqing & Chuzhou & Lu'an & Xuancheng \\
\hline$B_{1}$ & 96.485 & 98.056 & 97.933 & 97.229 & 97.658 & 96.724 & 97.353 & 97.948 & 97.580 & 97.566 \\
$B_{2}$ & 87.167 & 87.131 & 85.282 & 85.000 & 85.127 & 84.670 & 84.361 & 84.987 & 85.039 & 85.006 \\
$B_{4}$ & 97.785 & 97.756 & 98.010 & 97.997 & 97.770 & 97.768 & 97.615 & 97.855 & 97.820 & 97.822 \\
$B_{5}$ & 96.652 & 96.598 & 96.566 & 96.674 & 96.208 & 97.067 & 96.247 & 96.830 & 95.441 & 96.504 \\
$B_{6}$ & 98.309 & 98.276 & 98.420 & 98.199 & 98.124 & 98.168 & 98.230 & 97.987 & 98.072 & 97.944 \\
$\overline{\bar{B}}$ & 95.040 & 95.482 & 95.128 & 94.856 & 94.872 & 94.480 & 94.598 & 95.039 & 94.725 & 93.896 \\
\hline
\end{tabular}


Using the Combined average (3) in Table 1, we calculate the average exceeding standard rate of five categories of food pesticide residues in school canteens in 10 cities, and finally calculate the comprehensive exceeding standard rate of five categories of food pesticide residues, as shown in Table 8 .

There is no pesticide residue detection system for the county and rural markets, but there is a supervision system for meat products. The centralized slaughtering system for live pigs was implemented on February 18, 1998, and the centralized slaughtering system for all livestock and poultry was implemented on October 15, 2015. The designated slaughterhouse is responsible for the comprehensive health test of the livestock and poultry sent to the factory, and random sampling test of whether the livestock and poultry are fed antibiotics and clenbuterol hormone beyond the limit, the sampling rate shall not be less than $1 \%$. All livestock and poultry meat sold by merchants must hold the quarantine certificate issued by the designated slaughterhouse. In each county, we also visited three professional livestock farm. The government has higher subsidies for large-scale breeding. However, the purchase (self processed) and use of each kind of feed need a detailed journal. The complete name and manufacturer of the additive must be indicated. The drug and food regulatory authorities under their jurisdiction conduct random checks on feed ingredients and blood of breeding animals from time to time, and pursue responsibility for the problems found out and impose heavy penalties. Therefore, the vast majority of meat products sold in rural markets should be under the supervision of the government.

In order to grasp more about the agricultural residues of rural edible agricultural products, we divide the level of harmful substances exceeding the standard in the edible agricultural products into the following: $A_{1}$ does not exceed the standard, $A_{2}$ slightly exceeds the standard, $A_{3}$ obviously exceeds the standard, $A_{4}$ seriously exceeds the standard. The boundaries of these levels are fuzzy. We sent out 100 questionnaires in the urban farmers' markets of each county. There are 24 survey indicators in the questionnaire, and each indicator is attached with 5 options of $A_{1}$, $A_{2}, A_{3}, A_{4}, A_{5}$. The respondents are required to choose one for each indicator. The effective questionnaires collected in 10 counties were at least 81 and at most 96 . The proportion of each grade of each index is calculated by county, and the fuzzy membership relationship of 24 indexes in each county is obtained. For example, in the 87 valid questionnaires collected in Feixi County, the statistical results include $\widetilde{C}_{11} \rightarrow\left(\frac{18}{87}, \frac{28}{87}, \frac{17}{87}, \frac{14}{87}, \frac{10}{87}\right)=$ $(0.2069,0.3218,0.1954,0.1609,0.1150)$. From (5), we get the fuzzy evaluation matrix of 6 level I indicators in Feixi County, as shown in Table 9.

Using (6) and AHP weight of the level II indicators in Table 1, we get the first level evaluation results of 6 level I indicators in Feixi County.

Table 7 Average compliance rate of 20 indicators of school canteens in 10 counties (\%)

\begin{tabular}{|c|c|c|c|c|c|c|c|c|c|c|}
\hline & Feixi & Wuwei & Dangtu & Suixi & Zongyang & Fengyang & Linquan & Taihu & Jinzhai & Jingxian \\
\hline$C_{11}$ & 98.22 & 98.53 & 98.15 & 98.11 & 98.23 & 98.16 & 98.06 & 98.35 & 98.03 & 98.42 \\
\hline$C_{12}$ & 98.14 & 97.06 & 97.03 & 97.34 & 97.45 & 97.27 & 97.28 & 97.84 & 97.14 & 97.33 \\
\hline$C_{13}$ & 97.34 & 96.91 & 95.61 & 95.43 & 96.82 & 95.91 & 95.15 & 96.82 & 96.53 & 96.17 \\
\hline$C_{21}$ & 84.35 & 84.62 & 84.86 & 85.21 & 84.83 & 85.06 & 85.50 & 85.10 & 84.26 & 84.13 \\
\hline$C_{22}$ & 88.52 & 88.31 & 87.64 & 87.33 & 87.21 & 86.40 & 85.94 & 86.31 & 86.92 & 87.23 \\
\hline$C_{23}$ & 85.22 & 85.08 & 84.32 & 85.21 & 84.03 & 84.25 & 84.23 & 85.17 & 84.30 & 83.92 \\
\hline$C_{24}$ & 86.32 & 86.23 & 85.35 & 85.08 & 86.92 & 86.75 & 85.20 & 86.31 & 85.42 & 86.57 \\
\hline$C_{25}$ & 87.41 & 87.25 & 87.91 & 87.24 & 86.74 & 85.23 & 86.04 & 87.12 & 87.31 & 87.13 \\
\hline$C_{41}$ & 98.21 & 98.65 & 98.02 & 98.53 & 98.14 & 98.23 & 98.05 & 97.98 & 98.02 & 97.90 \\
\hline$C_{42}$ & 97.56 & 97.18 & 98.03 & 98.21 & 98.05 & 98.12 & 97.52 & 97.35 & 97.14 & 97.84 \\
\hline$C_{43}$ & 98.00 & 97.12 & 98.05 & 97.81 & 97.63 & 97.56 & 97.49 & 97.96 & 97.84 & 97.72 \\
\hline$C_{44}$ & 98.64 & 98.52 & 98.25 & 98.42 & 98.53 & 97.87 & 97.96 & 98.12 & 98.10 & 97.92 \\
\hline$C_{45}$ & 96.33 & 97.04 & 97.18 & 96.54 & 96.05 & 96.32 & 96.11 & 96.93 & 97.21 & 97.14 \\
\hline$C_{51}$ & 97.31 & 97.12 & 96.85 & 96.96 & 96.23 & 97.05 & 96.32 & 97.25 & 97.14 & 97.21 \\
\hline$C_{52}$ & 96.06 & 96.28 & 96.82 & 97.10 & 96.12 & 97.69 & 96.23 & 96.72 & 96.85 & 96.49 \\
\hline$C_{53}$ & 95.11 & 95.03 & 94.71 & 95.17 & 94.42 & 94.38 & 94.29 & 95.12 & 94.57 & 94.32 \\
\hline$C_{54}$ & 97.12 & 97.21 & 96.43 & 96.75 & 96.82 & 96.75 & 96.86 & 97.05 & 97.08 & 96.82 \\
\hline$C_{61}$ & 98.20 & 98.11 & 97.95 & 98.12 & 97.85 & 97.68 & 97.84 & 97.81 & 98.12 & 97.45 \\
\hline$C_{62}$ & 98.31 & 98.12 & 98.65 & 98.09 & 98.04 & 98.32 & 98.33 & 97.90 & 97.85 & 97.94 \\
\hline$C_{63}$ & 98.21 & 98.14 & 98.17 & 98.20 & 98.15 & 98.04 & 98.21 & 97.84 & 97.86 & 97.52 \\
\hline
\end{tabular}


Table 8 Classification and summary of average standard rate of 20 indicators in canteen of 10 counties (\%)

\begin{tabular}{|c|c|c|c|c|c|c|c|c|c|c|}
\hline & Feixi & Wuwei & Dangtu & Suixi & Zongyang & Fengyang & Linquan & Taihu & Jinzhai & Jingxian \\
\hline$B_{1}$ & 97.829 & 97.385 & 96.736 & 96.750 & 97.394 & 96.940 & 96.601 & 97.551 & 97.121 & 97.136 \\
\hline$B_{2}$ & 86.511 & 86.433 & 86.166 & 86.118 & 86.049 & 86.071 & 85.432 & 86.070 & 85.773 & 85.930 \\
\hline$B_{5}$ & 97.626 & 97.597 & 97.860 & 97.817 & 97.573 & 97.557 & 97.333 & 97.595 & 97.594 & 97.670 \\
\hline$B_{5}$ & 96.423 & 96.448 & 96.319 & 96.604 & 95.959 & 96.645 & 95.997 & 96.607 & 96.509 & 96.302 \\
\hline$\underline{B_{6}}$ & 98.242 & 98.121 & 98.257 & 98.129 & 97.992 & 97.800 & 98.108 & 97.850 & 97.959 & 97.644 \\
\hline $\bar{B}$ & 95.220 & 95.058 & 94.865 & 94.884 & 94.885 & 94.845 & 94.476 & 95.034 & 94.837 & 94.833 \\
\hline
\end{tabular}

$$
\begin{gathered}
\widetilde{r}_{1}=(0.3602,0.3834,0.2564) \circ R_{1}=(0.2069,0.3218,0.2564,0.2514,0.1779), \\
\widetilde{r}_{2}=(0.2131,0.1903,0.2035,0.1832,0.2089) \circ R_{2}=(0.1452,0.2131,0.2131,0.2131,0.2131), \\
\widetilde{r}_{3}=(0.2819,0.2651,0.2079,0.2451) \circ R_{3}=(0.1874,0.2257,0.2819,0.2431,0.2302), \\
\widetilde{r}_{4}=(0.2201,0.2210,0.2205,0.1603,0.1881) \circ R_{4}=(0.2205,0.2210,0.2210,0.1854,0.1749), \\
\widetilde{r}_{5}=(0.2556,0.2712,0.2086,0.2643) \circ R_{5}=(0.2086,0.2683,0.2643,0.2108,0.2019), \\
\widetilde{r}_{6}=(0.4202,0.3602,0.2196) \circ R_{6}=(0.1845,0.2634,0.2413,0.2342,0.1336) .
\end{gathered}
$$

From (7) and (8), using the weight of the level I indexes in Table 1, we get the second level fuzzy evaluation result of total evaluation indicator $\overline{\bar{B}}$ in Feixi County.

$$
\begin{aligned}
a \circ R= & (0.262,0.184,0.12,0.218,0.142,0.074) \\
& \circ\left[\begin{array}{lllll}
0.2069 & 0.3218 & 0.2564 & 0.2514 & 0.1779 \\
0.1452 & 0.2131 & 0.2131 & 0.2131 & 0.2131 \\
0.1874 & 0.2257 & 0.2819 & 0.2431 & 0.2302 \\
0.2205 & 0.2210 & 0.2210 & 0.1854 & 0.1749 \\
0.2086 & 0.2683 & 0.2643 & 0.2108 & 0.2019 \\
0.1845 & 0.2634 & 0.2413 & 0.2342 & 0.1336
\end{array}\right] \\
= & (0.218,0.262,0.2564,0.2514,0.184) .
\end{aligned}
$$

Because the maximum value of each row of matrix $R$ is in the second column, the second column, the third column, the second column, the second column and the second column respectively, and the maximum value of vector $a \circ R$ is in the second column, so for Feixi County, except the quality of indicator $B_{3}$ belongs to $A_{3}$, the rest of the quality of indicators belongs to $A_{2}$. In addition, according to (9), we can calculate the total membership of each indicator in Feixi County. Similarly, by processing the questionnaire data of other counties, we get the rating of each indicator and the corresponding total membership degree of 10 counties, which are listed in Table 10.

\section{investigation on the application of pesticides to rice growers}

Next, we take rice as an example to study the relationship between reducing pesticide application intensity and reducing harmful residues in food, as well as the impact on Farmers' income. Because the application of chemical fertilizer is convenient, labor saving and effective, and the price of organic fertilizer is expensive, bulky and bulky, farmers are used to applying more chemical fertilizer. Due to the long-term application of pesticides, pests have developed resistance, less application may reduce crop yield, so farmers usually try to apply as much as possible. Vegetables, especially leafy vegetables grown in summer, are most plagued by pests. Some vegetable farmers spray pesticides once a day or two. The greenhouse vegetables planted in off-season are more prone to insects, and the greenhouse is not easy to ventilate, the pesticide is not easy to emit, and the pesticide residue is heavier than that of open-air vegetables (see the research results of Tang et al. 2012). Because the vegetables planted by different vegetable growers may be different, and the growth periods of various vegetables are also different, there is no comparability in the application of pesticides. In grain crops, wheat mainly grows in cold season, and pesticide is relatively small. Rice and corn are easy to grow insects, and rice planting area is wide. In addition, the growth period of early rice and double cropping late rice is short, the yield is low, and the labor cost is almost the same as that of single cropping late rice. Single cropping late rice has a long growth period and many pesticides, but it has high yield and low labor cost. Farmers like to grow single cropping late rice. The pesticide of early rice is applied less, so the general farmers only grow a small amount of early rice every year, and keep them as their own rations, and then crop the double cropping late rice, and most of the land is planted with single-season late rice. We focused on 
Table 9 Fuzzy evaluation matrix of 6 level I indicators of pesticide residues in Feixi County
$B_{1}$

$R_{1}=\left[\begin{array}{lllll}0.2069 & 0.3218 & 0.1954 & 0.1609 & 0.1150 \\ 0.2105 & 0.2241 & 0.1862 & 0.2013 & 0.1779 \\ 0.1571 & 0.1964 & 0.3426 & 0.2514 & 0.0525\end{array}\right]$

$B_{2}$

$R_{2}=\left[\begin{array}{lllll}0.0254 & 0.2151 & 0.2563 & 0.2824 & 0.2208 \\ 0.1153 & 0.2246 & 0.2906 & 0.3105 & 0.0590 \\ 0.0845 & 0.1683 & 0.2235 & 0.2841 & 0.2396 \\ 0.1232 & 0.2219 & 0.2583 & 0.2453 & 0.1513 \\ 0.1452 & 0.2024 & 0.2431 & 0.2319 & 0.1774\end{array}\right]$

$B_{3}$ $R_{3}=\left[\begin{array}{lllll}0.1352 & 0.1463 & 0.2842 & 0.2431 & 0.1912 \\ 0.1874 & 0.1921 & 0.2951 & 0.2418 & 0.0836 \\ 0.1812 & 0.2863 & 0.2243 & 0.2305 & 0.0777 \\ 0.0543 & 0.2257 & 0.2591 & 0.2307 & 0.2302\end{array}\right]$

$B_{4}$ $R_{4}=\left[\begin{array}{lllll}0.3124 & 0.2317 & 0.2418 & 0.1243 & 0.0898 \\ 0.2154 & 0.2942 & 0.2218 & 0.1521 & 0.1165 \\ 0.2323 & 0.2547 & 0.2841 & 0.1854 & 0.0435 \\ 0.3321 & 0.2541 & 0.1847 & 0.1125 & 0.1166 \\ 0.1523 & 0.2621 & 0.2361 & 0.1746 & 0.1749\end{array}\right]$

$B_{5}$ $R_{5}=\left[\begin{array}{lllll}0.1487 & 0.2524 & 0.2389 & 0.2108 & 0.1492 \\ 0.1320 & 0.2683 & 0.2253 & 0.1725 & 0.2019 \\ 0.3122 & 0.2241 & 0.2014 & 0.1783 & 0.0840 \\ 0.1524 & 0.2319 & 0.2654 & 0.1532 & 0.1971\end{array}\right]$

$B_{6}$

$$
R_{6}=\left[\begin{array}{lllll}
0.1461 & 0.2631 & 0.2413 & 0.2342 & 0.1153 \\
0.1845 & 0.2634 & 0.2341 & 0.1844 & 0.1336 \\
0.1576 & 0.2853 & 0.2516 & 0.2149 & 0.0916
\end{array}\right]
$$

collecting the main tendency of pesticide application in single cropping late rice. Among the professional rice growers in each county, 480 households (at least 30 and at most 62 in each county) were selected and sent out questionnaires. The questionnaire includes four questions: (1) Do you work hard to prevent your products from being found to have excessive pesticide residues? (2) What do you think is the difficulty of increasing the amount of organic fertilizer in an all-round way at present, and what are the good suggestions. (3) How many times do you usually apply pesticides to early, middle and late rice? How many times do you apply herbicides? (4) What do you think is the extent to which the application of pesticides in accordance with normal conditions can basically ensure that the pesticide residues meet the national standards? For single cropping late rice production, respondents were required to give an interval $\left[a_{i}, b_{i}\right]$ for each indicator $X_{i}$ of 13 indicators such as chemical fertilizer, organic fertilizer and pesticide application, and the interval should be as short as possible.
1. Data collection and statistics

453 valid questionnaires were collected. Each indicator value is determined by fuzzy convex membership function method. Let all cells of the $i$ th indicator $(i=1,2, \cdots, 13)$ be $\left[a_{i j}, b_{i j}\right], j=1,2, \cdots, 875$. All the intersections of these cells are $\alpha_{i 0}, \alpha_{i 1}, \cdots, \alpha_{\text {in }}$, correspondingly, $n$ intervals $\left[\alpha_{i 0}, \alpha_{i 1}\right)$, $\left[\alpha_{i 1}, \alpha_{i 2}\right)$

$\cdots,\left[\alpha_{i n-2}, \alpha_{i n-1}\right),\left[\alpha_{i n-1}, \alpha_{i n}\right]$ are obtained. Mark the $n$ cells as $A_{i 1}, A_{i 2}, \cdots, A_{i n}$, respectively. In all intervals $\left[a_{i j}, b_{i j}\right]$, $j=1,2, \cdots, 875$, there is $r_{i 1}$ intersection with $\left[\alpha_{i 1}, \alpha_{i 2}\right)$ is not empty, there is $r_{i 2}$ intersection with $\left[\alpha_{i 2}, \alpha_{i 3}\right)$ is not empty, and so on, there are $r_{\boldsymbol{i n}}$ final intersection with $\left[\alpha_{\boldsymbol{i n}-1}, \alpha_{\boldsymbol{i n}}\right]$ is not empty. Using $X_{i}$ to represent the $i$ th evaluation indicator, we can first obtain the $\widetilde{X}_{i}$ of convex membership number of $X_{i}$.

$$
\begin{aligned}
\widetilde{X}_{i} & =\mu\left(X_{i}\right)=r_{i 1} / A_{i 1}+r_{i 2} / A_{i 2}+\cdots+r_{\text {in }} / A_{\text {in }} \\
& =\left(r_{i 1}, r_{i 2}, \cdots, r_{\text {in }}\right)
\end{aligned}
$$


Table 10 Classification and summary of food pesticide residues in 10 county farmers' markets

\begin{tabular}{|c|c|c|c|c|c|c|c|c|c|c|}
\hline & Feixi & Wuwei & Dangtu & Suixi & Zongyang & Fengyang & Linquan & Taihu & Jinzhai & Jingxian \\
\hline$B_{1}$ & $A_{2} 0.4354$ & $A_{2} 0.4412$ & $A_{2} 0.4278$ & $A_{2} 0.4513$ & $A_{2} 0.4233$ & $A_{2} 0.4431$ & $A_{2} 0.4273$ & $A_{2} 0.4312$ & $A_{2} 0.4334$ & $A_{2} 0.4424$ \\
\hline$B_{2}$ & $A_{2} 0.3592$ & $A_{3} 0.4240$ & $A_{2} 0.3391$ & $A_{3} 0.4528$ & $A_{3} 0.5011$ & $A_{3} 0.4523$ & $A_{3} 0.4815$ & $A_{2} 0.3523$ & $A_{4} 0.8306$ & $A_{4} 0.8271$ \\
\hline$B_{3}$ & $A_{3} 0.5949$ & $A_{2} 0.4014$ & $A_{2} 0.3915$ & $A_{3} 0.5852$ & $A_{3} 0.5623$ & $A_{2} 0.4253$ & $A_{2} 0.4022$ & $A_{2} 0.4715$ & $A_{3} 0.5724$ & $A_{2} 0.4117$ \\
\hline$B_{4}$ & $A_{2} 0.4317$ & $A_{2} 0.4323$ & $A_{3} 0.5215$ & $A_{2} 0.4296$ & $A_{2} 0.4357$ & $A_{2} 0.4203$ & $A_{2} 0.4210$ & $A_{3} 0.5183$ & $A_{2} 0.4194$ & $A_{2} 0.4302$ \\
\hline$B_{5}$ & $A_{2} 0.4133$ & $A_{3} 0.5403$ & $A_{2} 0.4122$ & $A_{2} 0.4315$ & $A_{3} 0.5289$ & $A_{3} 0.5203$ & $A_{3} 0.5541$ & $A_{2} 0.4224$ & $A_{4} 0.8625$ & $A_{4} 0.8705$ \\
\hline$\underline{B_{6}}$ & $A_{2} 0.4237$ & $A_{2} 0.4228$ & $A_{2} 0.4324$ & $A_{2} 0.4295$ & $A_{3} 0.5618$ & $A_{2} 0.4364$ & $A_{2} 0.4327$ & $A_{2} 0.4386$ & $A_{3} 0.5705$ & $A_{2} 0.4231$ \\
\hline $\bar{B}$ & $A_{2} 0.4096$ & $A_{3} 0.5627$ & $A_{2} 0.4102$ & $A_{2} 0.4015$ & $A_{3} 0.5643$ & $A_{3} 0.5721$ & $A_{3} 0.5627$ & $A_{2} 0.4122$ & $A_{4} 0.8719$ & $A_{4} 0.8633$ \\
\hline
\end{tabular}

Let

$L_{i}=\int_{\alpha_{i 0}}^{\alpha_{i n}} \widetilde{X}_{i} d X_{i}=\sum_{k=1}^{n} r_{i k}\left(\alpha_{i k}-\alpha_{i k-1}\right)$

and we have

$X_{i} \sim=\mu \sim\left(X_{i}\right)=\left(r_{i 1} / L_{i}, r_{i 2} / L_{i}, \cdots, r_{\text {in }} / L_{i}\right)$,

where $r_{i j}=r_{i j} / L(j=1,2, \cdots, n)$. We call $X_{\sim_{i}}$ the standardized convex membership number of $X_{i}$. By direct calculation, we get $X_{i}$ expected value and variance

$E\left(X_{i}\right)=\int_{\alpha_{i 0}}^{\alpha_{i n}} X_{i} \sim X_{i} d X_{i}=\frac{1}{2 L_{i}} \sum_{k=1}^{n} r_{i k}\left(\alpha_{i k}^{2}-\alpha_{i k-1}^{2}\right)$,

$$
\begin{aligned}
D\left(X_{i}\right) & =\int_{\alpha_{i 0}}^{\alpha_{i n}} \underset{\sim}{X}\left[X_{i}-E\left(X_{i}\right)\right]^{2} d X_{i} \\
& =\frac{1}{3 L_{i}} \sum_{k=1}^{n} r_{i k}\left(\alpha_{i k}^{3}-\alpha_{i k-1}^{3}\right)-\left[E\left(X_{i}\right)\right]^{2} .
\end{aligned}
$$

We set the evaluation value of $X_{i}$ as $E\left(X_{i}\right)$, and use $D\left(X_{i}\right)$ to judge the degree of concentration of the results of the questionnaire, that is, the credibility of the results. The smaller $D\left(X_{i}\right)$ is, the more credible it is. If $D\left(X_{i}\right)$ is too large, consider eliminating some interview results that are too different from $E\left(X_{i}\right)$. However, $D\left(X_{i}\right)$ cannot exceed much, there is no absolute standard at present, generally determined according to experience. Finally, the data are sorted out as shown in Table 11:

Among them, comprehensive labor includes labor tool loss, breeding, fertilization, pesticide application, and field management; harvesting has been fully mechanized; and seedling planting on large land has also been mechanized. The statistical results of the four questions are as follows: (1) All respondents wanted to avoid exceeding the standard of agricultural residues in the products harvested, but they were more worried about the reduction of production. (2) More than $87 \%$ of the respondents believed that the main reason was that the price of organic fertilizer was high and the effect of organic fertilizer was slow. Excessive application of organic fertilizer immediately might affect the current yield. The important measure to expand the source of organic fertilizer was to realize the cooperation between planting and animal husbandry. Therefore, the average proportion of organic fertilizer is only $20.1 \%$. (3) Early rice, double cropping late rice and single cropping late rice were sprayed with insecticide 3 times, 7 times and 8 times respectively. Generally, herbicides were applied twice in each season. There are mainly two kinds of chemical fertilizers used in rice. Before planting seedlings, more compound chemical fertilizers are used as base fertilizer, and then nitrogen fertilizer is added 2-3 times according to the growth of seedlings. (4) According to the experience of $79 \%$ of the respondents, if the control effect is controlled within $85 \%$, the pesticide residues can basically pass the test.

\section{Parameter estimation}

According to (10), in this paper, we take $C(T)=1-$ $\exp (-m T)$; thus, we get

$y=a x_{1}^{\beta_{1}} x_{2}^{\beta_{2}}(1-\delta)+\delta a x_{1}^{\beta_{1}} x_{2}^{\beta_{2}}[1-\exp (-m T)]$,

where $y=X_{1}, x_{1}=X_{4}, x_{2}=X_{5}+X_{7}+X_{12}, T=X_{6}, C(T)=X_{8}$ (see Table 11). Let $\delta$ be about 0.3, and from (11) we get the regression equation

$\widehat{y} /\left(1-0.3 e^{-m T}\right)=a x_{1}^{\beta_{1}} x_{2}^{\beta_{2}}$.

In order to estimate the parameters of regression equation (12), we do it in two steps.

Step 1 Because $m=-\frac{1}{T} \operatorname{Ln}[1-C(T)]$, according to the original sample data of pesticide input and pest control effect collected from 10 counties, the moment estimation method is used to obtain the estimated value of $m$ in (11).

$\widehat{m}=-\frac{1}{875} \sum_{j=1}^{875} n\left[1-C\left(T_{j}\right)\right] / T_{j} L=0.02186$. 
Table 11 Production cost, yield and price of single cropping late rice in 10 counties

\begin{tabular}{|c|c|c|c|c|}
\hline & $E\left(X_{i}\right)$ & $\alpha_{\text {in }}$ & $\alpha_{i 0}$ & $\sqrt{D\left(X_{i}\right)}$ \\
\hline Per mu yield $X_{1}(\mathrm{~kg})$ & 507.8 & 518 & 490 & 32.6 \\
\hline Price $X_{2}$ (yuan $\left./ \mathrm{kg}\right)$ & 4.2 & 4.5 & 4.0 & 0.26 \\
\hline Seed $X_{3}($ yuan $/ \mathrm{mu})$ & 27.3 & 29.0 & 26.0 & 2.2 \\
\hline Fertilizer $X_{4}($ yuan $/ \mathrm{mu})$ & 122.8 & 152.0 & 104.5 & 22.7 \\
\hline Apply fertilizer $X_{5}$ (yuan/mu) & 102.8 & 122.0 & 97.5 & 20.5 \\
\hline Pesticides $X_{6}($ yuan $/ \mathrm{mu})$ & 105.2 & 131.5 & 97.5 & 30.4 \\
\hline Application $X_{7}$ (yuan/mu) & 102.1 & 113.5 & 97.5 & 18.7 \\
\hline Application effect $X_{8}(\%)$ & 90.1 & 92.5 & 86.0 & 3.6 \\
\hline Tractor-ploughing $X_{9}$ (yuan/mu) & 102.0 & 112.5 & 88.0 & 8.7 \\
\hline Agricultural film $X_{10}$ (yuan/mu) & 7.1 & 8.0 & 6.5 & 0.8 \\
\hline Irrigation $X_{11}$ (yuan/mu) & 10.2 & 11.0 & 10.0 & 0.91 \\
\hline Comprehensive labor $X_{12}$ (yuan/mu) & 195.2 & 235.0 & 172.0 & 17.3 \\
\hline Proportion of organic fertilizer $X_{13}(\%)$ & 20.1 & 31.0 & 16.5 & 3.3 \\
\hline
\end{tabular}

Note: According to the experience of $79 \%$ of the respondents, if the control effect is controlled within $85 \%$, the pesticide residues can basically pass the test

where $T_{j}=\left(a_{6 j}+b_{6 j}\right) / 2$, that is the average value of pesticide application intensity given by interviewee $j$-th. Similarly, $C\left(T_{j}\right)=\left(a_{8 j}+b_{8 j}\right) / 2$.

Step $2 y^{*}=\operatorname{Ln}\left[y /\left(1-0.3 e^{-0.02186 T}\right)\right], x_{1}^{*}=\operatorname{Ln} x_{1}, x_{2}^{*}=$ $\operatorname{Ln} x_{2}, a^{*}=L n a$, is recorded, and (12) is transformed into binary linear regression equation

$\widehat{y}_{i}^{*}=a^{*}+\beta_{1} x_{1 i}^{*}+\beta_{2} x_{2 i}^{*}(i=1,2, \cdots, n)$.

Using the data of 453 sample households and Mathematica software, the estimation can be obtained by the ordinary least squares method.

$$
\begin{aligned}
& \widehat{a}^{*}=1.59066, \widehat{\beta}_{1}=0.211, \widehat{\beta}_{2}=0.61, \\
& \quad \text { so } \widehat{a}=4.907,(11) \text { is } \\
& \widehat{y}_{j}=4.907 x_{1 j}^{0.211} x_{2 j}^{0.61}\left(1-0.3 e^{-0.02186 T_{j}}\right)(j=1,2, \cdots, 453) .
\end{aligned}
$$

The regression equation of rice Damage-abatement production function is obtained.

\section{Validity test}

The validity of the equation (14) was tested by $F$-test, and $H_{0}: \beta_{1}=\beta_{2}=0$ is assumed. Let $Q_{e}=\sum_{i=1}^{30}\left(y_{i}-\widehat{y}_{i}\right)^{2}, U=\sum_{i=1}^{30}$ $\left(y_{i}-\bar{y}\right)^{2}, F=\frac{U / 2}{Q_{e} /(30-2-1)}$. directly from the sample data and (14), we can directly calculate $F=23.84$. Taking the significance level $\alpha=0.05$, we look up the critical value table and get the critical value $F_{0.95}(2,27)=19.5<23.84$, that is, we refuse to assume $H_{0}$, so the regression equation (14) is valid, and further (15) is valid. Equation (15) shows that the contribution rate $\beta_{2}$ of labor input to rice yield in the investigated area is much larger than that of fertilizer $\beta_{1}$. The main reason is that too much fertilizer is used in rice production at present, and the effect of fertilizer on rice yield is extremely weak. The effect of field management on rice yield is still very significant.

\section{Results and analysis}

\section{Analysis of pesticide residues exceeding the standard}

According to Table 4, Table 6, Table 8 and Table 10, we calculated the average value of harmful residues in 10 cities and 10 counties respectively, and obtained the total standard situation of harmful residues in agricultural products consumed in urban and rural areas (see Table 12 and Fig. 2). In order to change the compliance degree of pesticide residues in rural food market into percentage, we first regard $A_{1}, A_{2}, A_{3}$, $A_{4}$ and $A_{5}$ as $100 \%, 80 \%, 60 \%, 40 \%$ and $20 \%$ respectively, and then calculate according to the following method. If the index $B_{i}$ (or $\overline{\bar{B}}$ ) of a county reaches grade $A_{j}$ and the total membership degree is $\widetilde{S}_{i}$ (or $\widetilde{S}_{T}$ ), then the standard degree of index $B_{i}$ (or $\overline{\bar{B}}$ ) of the county is $20 \%\left(5-j+\widetilde{S}_{i}\right)+5 \%$, or $20 \%\left(5-j+\widetilde{S}_{T}\right)+5 \%$. If we count the quality up to $A_{j}$ as just above the bottom line, it is obviously too low, so we increase it by $5 \%$. For example, the first level indicator $B_{1}$ of Feixi County reaches $A_{2}$ level with membership degree of 
Table 12 Summary of pesticide residue detection and questionnaire of edible agricultural products

\begin{tabular}{llllllrr}
\hline & $B_{1}$ & $B_{2}$ & $B_{3}$ & $B_{4}$ & $B_{5}$ & $B_{6}$ & $\overline{\bar{B}}$ \\
\hline City market & 93.078 & 84.799 & 97.120 & 95.374 & 95.435 & 94.907 \\
City school & 97.453 & 85.377 & $*$ & 97.820 & 96.479 & 98.083 \\
Rural market & 73.6928 & 65.04 & 67.6368 & 69.92 & 61.112 & 70.143 \\
Rural school & 97.144 & 86.055 & $*$ & 97.422 & 96.381 & 98.010 \\
\hline
\end{tabular}

0.4354 , that is, the first level indicator $B_{1}$ of Feixi County reaches $A_{3}$ level or above, so the compliance degree of the first level indicator $B_{1}$ of Feixi County is evaluated as $20 \%(5-2+0.4354)+5 \%=73.708 \%$.

In urban and rural schools, except for vegetable indicator $B_{2}$, which was $85.377 \%$ and $86.055 \%$ respectively, the other four level I indicators and comprehensive indicator $\overline{\bar{B}}$ were all around $95 \%$. In the urban farmer's market, except for vegetable indicator $B_{2}$, which only reached $84.779 \%$, the other five level I indicators and comprehensive indicator $\overline{\bar{B}}$ reached 92.961-97.12\%. In the rural market, only $B_{1}$ and $B_{6}$ are slightly higher than $70 \%$ of the standard, and the other indicators are slightly higher than $60 \%$ of the standard. A careful review of Table 10 shows that there is a large gap in the degree of reaching the standard of pesticide residues among counties. Feixi, Dangtu, Suixi and Taihu counties, which are relatively developed, are slightly better than Jinzhai and Jing counties, which are relatively backward in mountainous areas. It may be that rural people with better economic conditions pay more attention to pesticide residues when buying food, and producers must be more cautious when applying pesticides.

In addition, in the market survey, we noticed that the vast majority of edible agricultural products consumed by urban residents come from large-scale farmers' markets. The total amount of individual businesses and night markets is very small, and individual businesses are also monitored to a certain extent. Therefore, we estimate that at least $95 \%$ of edible agricultural products consumed by urban residents is under the supervision of the government. All urban school canteens are under the supervision of the government. Although rural school canteens are under strict management, especially many schools often conduct self inspection, the inspection interval of the supervision department is generally two months. So we assume that $95 \%$ of the rural school canteens are monitored by the government. For the edible agricultural products consumed by rural residents, only livestock and poultry are slaughtered intensively, and random sampling is carried out for the feeding process of large-scale farms, so the safety performance of meat food is basically guaranteed. For the planting industry, the main measures are to guide and encourage farmers to use less chemical fertilizers and pesticides, and the monopoly system and real name system are adopted for the purchase of chemical fertilizers and pesticides and veterinary drugs. Considering that the implementation of centralized slaughtering system may not be strict, we estimate that the government's monitoring degree on the production of edible agricultural products is about $30 \%$. In addition, for the questionnaire survey of the rural market, although we mainly choose housewives who know the most about food quality as the respondents, we feel that the respondents tend to give high evaluation as much as possible. Therefore, the comprehensive compliance rate of rural residents' consumption of edible agricultural products reflected in Table 10 is $60.261 \%$. We estimate that it may be less than $60 \%$ in fact, that is, it obviously exceeds the standard. At present, the theoretical accuracy rate of rapid detection instruments used in the market is $95 \%$, but
Fig. 2 Total results of pesticide residues test and questionnaire of edible agricultural products $(\%)$

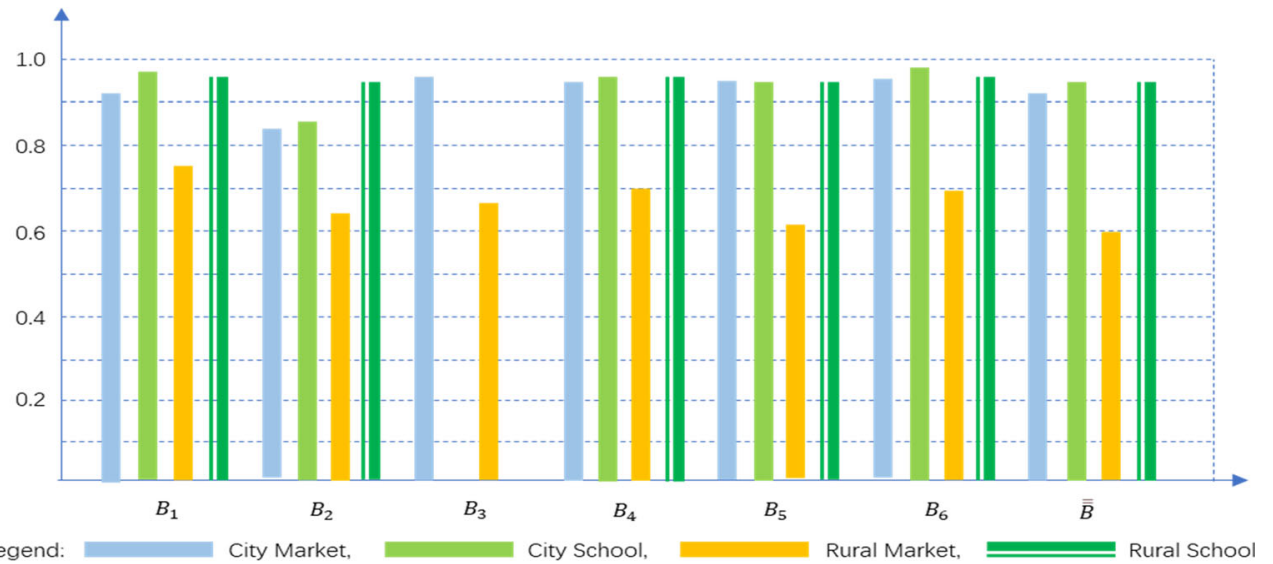


in order to speed up the promotion of rapid detection technology, the government has a low threshold for the production access of detection instruments, and the production enterprises are mixed. According to some market testers, the actual accuracy of testing instruments is about $90 \%$. We use Fig. 3 to describe the overall actual situation of harmful residues in edible agricultural products.

Figure 3 shows that the food safety rate of school canteens is the highest, and the food safety of rural school canteens is not different from that of urban ones. The safety of edible agricultural products consumed by urban residents basically reached $80 \%$. Only the residues of harmful substances in edible agricultural products consumed by rural residents obviously exceeded the standard. The food suppliers of the school canteen know that the school is strict, and they automatically try to avoid providing items with excessive pesticide residues. The fact also shows that the producers of agricultural products know the degree of pesticide residues in the food they provide.

\section{Analysis on the causes of excessive pesticide residues in edible agricultural products}

Using (12), we can estimate the profit of rice production per $\mathrm{mu}$

$R_{j}=\widehat{y}_{j} X_{2 j}-\left(X_{3}+X_{4}+\cdots+X_{8}+X_{10}+X_{11}+X_{12}\right)$.

For example, according to Table 11, the average profit per $\mathrm{mu}$ of 543 households is 1358.06 yuan. In the rice production of the $j$-th cooperative, if the input per mu is $x_{1}=115.8$ yuan for chemical fertilizer, $x_{2}=339.4$ yuan for labor and $T_{j}=105$ yuan for pesticide, the application effect $C\left(T_{j}\right)=0.96978$, the yield per mu is $y_{j}=500.95 \mathrm{~kg}$ and the profit per mu is $R_{j}=$
1212.19 yuan. According to the notes in the last line of Table 11, the $j$-th cooperative now plans to control the pest control effect below $85 \%$, so that the pesticide residue may reach the standard, that is, $1-0.3 e^{-0.02186 T_{j}}<0.85$, then the pesticide application intensity $T_{j}<31.71$ yuan. The yield per $\mathrm{mu}$ is $y_{j}=439.07 \mathrm{~kg}$, and the profit per mu is reduced to $R_{j}=$ 1028.23 yuan. Therefore, the cooperative would rather apply more pesticides than bear the consequences of lower production. This is also a common phenomenon in all crop cultivation. It can be seen that the phenomenon of excessive pesticide residues in agricultural source food is not optimistic. According to the research of scholars, only about $20 \%$ of the pesticides are absorbed by crops (Wang and Gu 2013), and only $20 \%$ of the pesticides absorbed by crops are contained in rice, and the rest is in straw (Zhang et al. 2011). In addition, according to the experience of farmers, the pesticide residues in rice will be further attenuated when rice is stored at home for a period of time, so the pesticide residues in rice are not particularly serious. For vegetables that are not protected by thick skin outside, pesticides usually directly enter into vegetables, and vegetables cannot be stored at home for a long time, so the pesticide residues in vegetables are the most serious.

\section{Conclusion}

Through the detection of pesticide residues in sales channels, it can greatly reduce the excessive pesticide residues in agricultural products. Edible agricultural products in Chinese cities and all kinds of school canteens are strictly tested for pesticide residues. On the whole, the pesticide residues in agricultural products are in a controllable

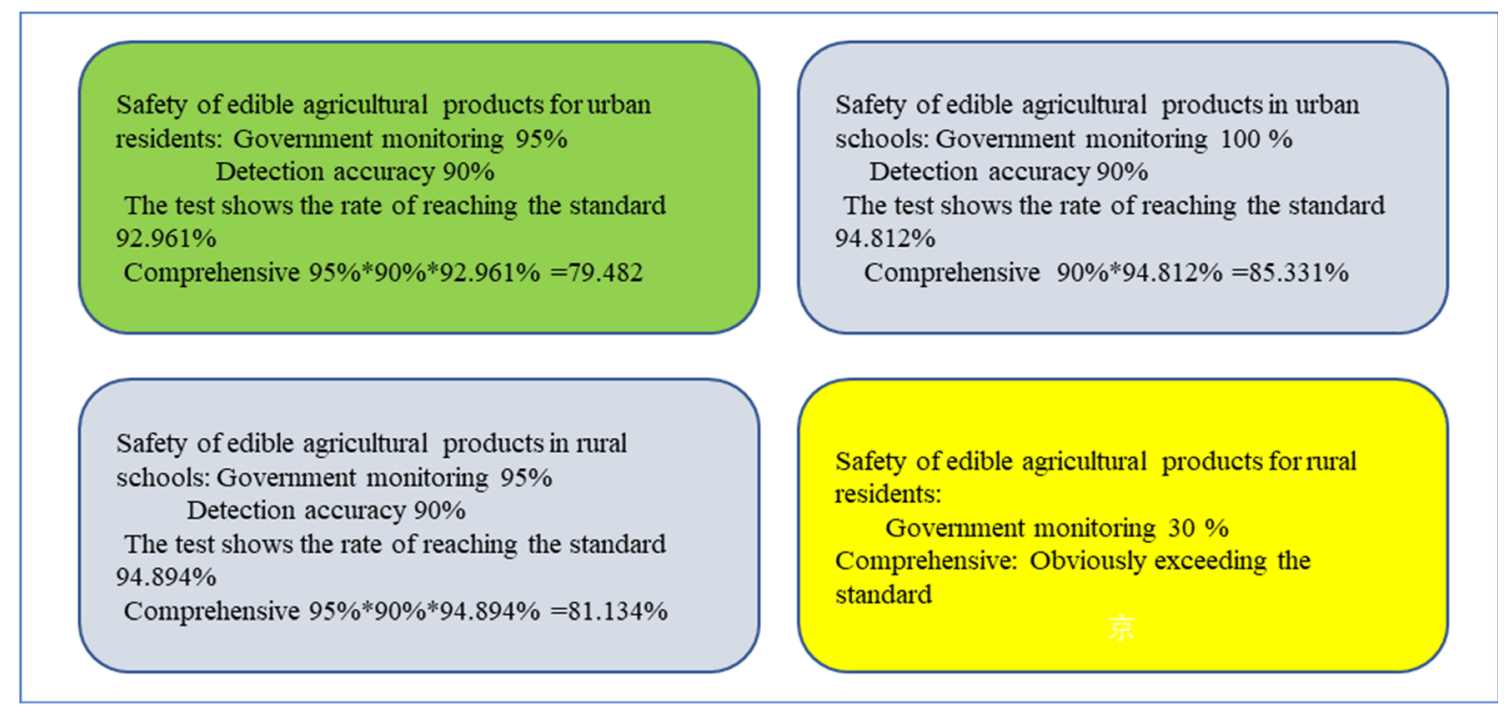

Fig. 3 The overall actual situation of harmful residues in edible agricultural products 
range. First of all, there are still some defects in market detection: (1) The accuracy of rapid detection can reach 95\% in theory, but it may be even lower in practice. The detection results can only play a role in preliminary investigation. In some markets, we have learned from our exchanges with operators that for the food that is found to be unqualified after investigation, it is generally only required to stop selling, not to investigate the source, not to punish and not to publicize. Moreover, every market sells a lot of agricultural products every day, and the proportion of random sampling is still too small, so the problem food must exist objectively (see the case in the introduction). (2) For the qualified food, the detection does not distinguish the specific degree of food residue, and lacks incentive mechanism for the operators of slightly better quality food. (3) Because the county, town, market town and the farmers' market in rural areas have not yet established the detection system of pesticide residues, it is inevitable that the edible agricultural products which does not meet the standard of pesticide residues will flow into the suburbs, roadside restaurants and rural areas. In particular, influenced by COVID-19, the government has liberalized the stall economy, and some unlicensed vegetables and fruit stalls on the streets have not been able to control the pesticide residues. Secondly, the risks of agricultural products reduction and pesticide residues borne by farmers are obviously asymmetric. Although governments at all levels have been guiding and rewarding farmers to use fertilizers, pesticides and veterinary drugs rationally, they are unable to strictly supervise the production process of farmers. According to Damage-abatement production function including pesticide factors, under certain conditions of fertilizer and labor input, rice yield and pesticide residue intensity are positively correlated with pesticide application intensity input, and most farmers know that rational application of pesticide can reduce pesticide residue. Reducing the use of pesticides will inevitably bear the risk of reducing the output of agricultural products, and applying more pesticides will increase the risk of pesticide residues. As the current farmers' market is not very strict on the detection of pesticide residues, farmers need to bear the risk of pesticide residues is very small. Driven by economic interests, farmers prefer to increase the intensity of pesticide application. Thirdly, the production cost and income of agricultural products are asymmetric. The cost of agricultural production is rising, but due to the influence of low prices in the international market and the low income of most people in China, the price of edible agricultural products is unlikely to rise significantly. Limited by financial resources, local governments cannot give too high subsidies to agricultural production reduction. What is more important is that there are too many people and too little land in China. If there is a large reduction in grain production, it will cause food shortage. Food belongs to strategic materials and cannot be heavily imported. Therefore, it is impossible to comprehensively promote the pesticide residue detection system in the short term, and the qualified standard will not be set too high. In recent years, China has taken measures such as resuming the consumption tax of chemical fertilizer, increasing the subsidy for organic fertilizer application, promoting the technology of soil testing and fertilization, processing organic fertilizer with garbage, and forcing livestock manure to process organic fertilizer. Gradually increasing the proportion of organic fertilizer in agricultural production will become a reality. Before there is a major breakthrough in the development of biological pest control technology, it may still be a protracted war to achieve a substantial reduction in the use of pesticides and veterinary drugs, which may also be a world problem.

The development of society has never been smooth sailing, but spiraling. The progress of agricultural science and technology, in reducing crop diseases and pests, improve food production, reduce the risk of hunger, at the same time, increase the risk of food pollution. Just like the progress of transportation, it brings convenience for people to travel, but increases the risk of traffic accidents. The food pollution risk is mainly affected by lowincome groups, especially the majority of rural residents. Some people compare the difference between urban and rural areas in China to "cities like Europe, rural areas like Africa", which may still exist in the short term.

Of course, Chinese farmers generally lack scientific knowledge of pesticides, and their application behavior is blind, especially the law of pesticide application interval and pesticide residues cannot be accurately grasped. Strengthening the popularization of agricultural science and technology knowledge as soon as possible is an important link in the implementation of pesticide reduction measures. However, with the development of rapid detection technology, the price of simple rapid detection instrument is very cheap, and it may be popularized to families in the near future. The residues of harmful substances in food will become more and more transparent, and the food safety of the whole people will be greatly improved.

However, with the development of rapid detection technology, the price of simple rapid detection instrument is very cheap. It may be popularized to families in the near future, and the food safety of the whole people will be greatly improved.

There are two deficiencies in our research: (1) The information we have obtained from our investigation is limited, so it is certainly not comprehensive enough to reflect the problems in Chinese food. In particular, the results of the questionnaire survey in rural farmers' markets can only reflect part of the real situation of food pesticide residues in rural areas. (2) 
As the rural market did not implement pesticide residue detection, some fake and inferior food processed by black workshops were mainly sold in rural areas. For example, bean products processed with rotten and deteriorated soybeans (added with a toxic bleaching agent "suspended white block"), fruits ripened by spraying drugs, gutter oil, etc. In 2018 , Nanjing police intercepted a batch of zombie meat illegally entering the country. In the vast rural farmers' markets, how many of these harmful fake and inferior food are mixed with normal food. Due to the lack of reliable data, we did not study it.

Acknowledgements This work is partially supported by Key project of national social science fund (No. 18AGL001); Natural Science Project of Colleges and Universities in Jiangsu Province (19KJB550009).

Author contribution This research topic and research framework were proposed by Tao Sun, Wei Xu completed the data collection and specific research, and completed the writing of the paper.

Funding The funds used in this study are derived from government projects and do not accept any funding from enterprises or individuals. There is no conflict of interest.

Data availability The data and materials used in this paper come from four aspects: (1) published journal papers; (2) public statistical information published by government departments; (3) visit survey of our research group. It does not involve infringement of the interests and rights of any enterprise or individual. All data generated or analysed during this study are included in this published article [and its supplementary information files].

\section{Declarations}

Ethics approval and consent to participate Not applicable

Consent for publication Not applicable

Conflict of interest Professor Tao Sun is Wei Xu's doctoral supervisor. The relationship between the two is harmonious and there is no conflict of interest. There is no conflict of interest with any other organization or individual.

\section{References}

Bernd M (2015) Is current EU food safety law geared up for fightling food fraud? J Consum Protect Food Saf 10(S1):S19-S23

Cheng N, Dong K, Huang KL, Zhai BQ, Xu WT (2017) Development and Application of Test Paper for Rapid Quantitative Determination of Formaldehyde Residues in Aquatic Products. Chin Food J 17(10):254-261

Fan XP, Chen S, Zhang JS (2012) Application of improved osculating value method based on entropy weight in comprehensive evaluation of water quality. Environmental Protection and Circular Economy 14(4):42-45
Feng MX, Chen ZD, Yuwei Yuan YW, Chen XH, Lian ZX (2007) Study on the degradation dynamics of several pesticides in open field cucumber. Pesticide Sci Manag 28(5):17-20

Fox G, Weersink A (1995) Damage control and increasing returns. Am J Agric Econ 77(1):33-39

Hall DC, Norgaard RB (1973) On the timing and the application of pesticides. Am J Agric Econ 55(2):198-201

He YG, Su L, Hu YL (2013) Measures to ensure the safety of food of animal origin. Chin AnimHusband 2:40-42

Hongqian H, Xiumei L, Guangrong L, Zuzhang L, Yiren L, Yonglan H, Jianhua J, Caihong S, Fuquan W, Hou HQ, Liu XM, Liu GR, Li ZZ, Liu YR, Huang YL, Ji JH, Shao CH, Wang FQ (2011) Effects of combined application ratio of organic and inorganic fertilizers on Rice Yield and soil fertility in red soil paddy field. China Agricultural Sciences 44(3):516-523

Hou B, Ying RY (2014) A provincial comparative study on Farmers' cognition of pesticide residues. Statist Inform Forum 29(2):101-106

Huang QL, Chen RJ (2008) Technical Information Knowledge, Risk Preference and Pesticide Application by Farmers. Manag World 5:71-76

Jacquet F, Butault JP, Guichard L (2011) An Economic analysis of the Possibility of Reducing Pesticides in French Field Grops. Ecol Econ 70(9):1638-1648

Li JC (2013) Effects of nitrogen fertilization on chlorophyll fluorescence change in maize (Zea mays L.) under waterlogging at seedling stage. J Food Agric Environ 11(1):545-552

Li XB, Hao Chen H, Shen J (2012) Mathematical model of degradation dynamics of buprofezin in rice. Hubei Agric Sci 51(18):4101-4125

Li Z, Ding N, Guo LY, Meng J, Li J, Li X, Zheng YH, Wu GL, Zeng Y (2013) Effects of different proportions of organic fertilizer and chemical fertilizer on growth, yield and quality of winter wheat summer maize. Shandong Agric Sci 45(7):71-82

Riccardo R, Massimiliano G, Gregorio G (2013) Comparison of fuzzybased and AHP methods in sustainability evaluation: a case of traffic pollution-reducing policies. Eur Transp Res Rev 5(1):11-26

Schreinemachers P, Tipraqsa P (2012) Agricultural pesticides and land use intensification in high, middle and low income countries. Food Policy 37(6):616-626

Shen DZ (2011) Harm and preventive measures of herbicides. Agric Technol Service 28(12):1688-1689

Shi YJ (2012) Control effect of different doses of 45\% chlorpyrifos EC on rice stem borer. Agric Disaster Res 2(01):21-22

Sun JL (2010) Thinking about the harm of excessive application of chemical fertilizer. Modern Agric Sci Technol 16:278-279

Sun BG, Wang J (2018) Present Situation and Development Strategy of Chinese Food Industry. Chin J Food 18(8):1-6

Talpaz H, Borosh I (1974) Strategy for Pesticide Use: Frequency and Applications. Am J Agric Econ 56(4):769-775

Tang YL, Wang ZW, He AF, Huang JX (2012) Distribution characteristics of chlorothalonil and chlorpyrifos in Cucumber under protected environment. J Zhejiang Univ Technol 40(3):289-294

Velthof GL, Oudendag D, Witzke HP (2009) Integrated assessment of nitrogen emissions from agriculture in EU-27 using MITERRAEurope. J Environ Qual 38:402-417

Wagale M, Singh A (2019) The Application of Adaptive Neuro-Fuzzy Inference System and Fuzzy Delphi Technique to Assess SocioEconomic Impacts of Construction of Rural Roads. Transp Telecommun J 20(4):325-345

Wang CW, Gu HY (2013) Market VS government, what forces affect the choice of pesticide dosage in Chinese vegetable farmers. Manag World 11:50-188

Yan S, Zheng GP, Ma Y, Zhao Y, Cai YS, Li DD, Zheng Y, Pan SJ (2014) Effect of organic fertilizer and its combination with chemical fertilizer on quality of rice Kongyu 163. J Heilongjiang Bayi Agric Univ 2:13-16 
Yang K, Wen Q, Xia SY, Zhao R (2019) Analysis of Grain Production and Cultivated Land Resources Security in Shaanxi, Gansu, Ningxia and Mongolia. Sci Surv Map 44(7):67-73,81

Zhang XM, Zhang CZ (2011) Safety of four pesticides on rice. Jiangsu Agric Sci 1:349-350

Zhang XL, Ding XL, Qian YH, Wang ZQ (2011) Effect of pesticide application on pesticide residues in rice before and after heading. World Pesticide 33(2):30-33
Zhang K, Feng TZ, Xiong C, Zhang Z (2019) Top layout and implementation progress of comprehensive technology research and development of chemical fertilizer and pesticide application reduction and efficiency increase in China. J Plant Protect 46(5):943-953

Publisher's note Springer Nature remains neutral with regard to jurisdictional claims in published maps and institutional affiliations. 